\title{
Research and Application of Radial Borehole Fracturing Based on Numerical Simulation
}

\author{
Xiaolong Li $(D)$ and Jiayuan He \\ SINOPEC Petroleum Exploration and Production Research Institute, Beijing 100083, China \\ Correspondence should be addressed to Xiaolong Li; lixl2018.syky@sinopec.com
}

Received 24 June 2019; Revised 22 August 2019; Accepted 21 October 2019; Published 20 November 2019

Academic Editor: Constantinos Loupasakis

Copyright (C) 2019 Xiaolong Li and Jiayuan He. This is an open access article distributed under the Creative Commons Attribution License, which permits unrestricted use, distribution, and reproduction in any medium, provided the original work is properly cited.

\begin{abstract}
The radial borehole fracturing technology has been applied in a certain number of oilfields with good results being achieved. However, the morphology and variation of fracture still require further study. In this paper, the reservoir model based on formation fluid-solid coupling equation is established with the extended finite element method (XFEM) in ABAQUS, and the fracture morphologies in the single-radial borehole, vertical multiradial borehole, and horizontal multiradial borehole are simulated and analyzed with criteria of maximum principal stress and maximum energy release rate as the damage mechanism. Moreover, the accuracy of numerical simulation results is verified with the large-scale true 3D physical simulation experiment. The results show that the induced stress field along the radial borehole during fracturing is the root cause of fracture directional propagation along the radial borehole whose effective guidance distance reaches $40 \mathrm{~m}$. The vertical multiradial borehole can effectively enhance fracture directional propagation and is capable of reducing fracture initiation pressure. In the horizontal multiradial borehole, the major fracture propagating along each radial borehole is formed in the remote-borehole area, and the secondary fracture connecting the neighboring radial boreholes is formed in the near-borehole zone. Coordination of major and secondary fractures can effectively increase the drainage area and reduce the flow resistance in the near-borehole zone. Based on the research on fracture morphology of multiradial borehole fracturing, the scheme of radial borehole arrangement is optimized and verified through numerical simulation of deliverability. The final optimum borehole arrangement scheme is the intersectional angle of $45^{\circ}$ between four orthogonal radial boreholes and horizontal maximum principal stress.
\end{abstract}

\section{Introduction}

During fracturing in the wells of perforation completion, the dual-wing fracture propagating along the maximum principal stress is always formed, and the fracture network is not likely to occur [1-4]. Moreover, when not being distributed along the maximum principal stress, the remaining oil is not able to be connected by the conventional dual-wing fracture, significantly reducing the effect of stimulation [5].

The radial borehole fracturing technology based on hydraulic jetting technology has been applied experimentally in several oilfields of SINOPEC, with good results being achieved. In this paper, radial borehole fracturing technology means fracturing based on the existing radial boreholes drilling by hydraulic jetting technology. Based on the mature technology of hydraulic jetting [6-9], preliminary conclusions have been obtained in the research on the radial borehole fracturing at a certain level, which indicates that this technology can change the inherent morphology of fracture and effectively improve the effect of reservoir stimulation $[10,11]$.

Some studies about fracture initiation, fracture propagation, well stability, productivity, and so on have been conducted. The results are shown as follows.

In the fields of fracture propagation and the influence factor, both simulation and experiment were conducted. The fracture propagation path of single radial well was studied based on XFEM, and a two-dimensional model was established. The results show that the diameter of radial well and the azimuth are the major influence factors of failure pressure [12]. Also, the quantitative analysis on different parameters of fracture initiation pressure and fracture starting point 
was arranged to study local stress accumulation situation. The result shows that initiation pressure and distance between well and fracture starting point increases as the length, diameter, and azimuth of radial well section rise [13]. Another further quantitative analysis was introduced to quantify the guidance of radial borehole row in the vertical multiradial well fracturing. The results show that the directional propagation of fracture is realized through scientifically arranged vertical radial borehole row [14]. By synthesizing the previous studies, the law of influence factors on fracture propagation is preliminarily clarified which is as the radial borehole azimuth increases, the preferential rock tensile fracturing in the axial plane of radial boreholes becomes increasingly difficult. The increase of the radial borehole diameter can enhance the guiding strength $[15,16]$. Furthermore, the prediction methods of fracture starting point and fracture morphology were available $[17,18]$.

In terms of multiwells, experiments with true triaxial fracturing simulation system and numerical simulation were adopted to analyze the influence of different lateral lengths, counts, and azimuths on the fracturing initiation and propagation. The results show that the breakdown pressure will decrease by increasing the lateral length and count; the optimal lateral design for horizontal initiation is four laterals with the phase of $90^{\circ}$, and each lateral is at $45^{\circ}$ from the horizontal stress [19].

Regarding well stability, the influence of radial well on well stability was studied according to the criteria of Mises, Tresca, and MAXPS by a finite element method. Mises and Tresca grow with the diameter of radial well, azimuth, and horizontal stress difference rising. Max Principle is negatively correlated with the diameter of radial well and azimuth and positively correlated with the horizontal stress difference [20].

Concerning productivity, a calculation model of distal radial shaft fracture was derived based on the complex potential theory and the mirror image principle. The results show that the flux distribution diagram of radial well is groove shaped, and the flux distribution is large at the heel side and the toe side, while the middle is small and average [21].

Based on the pressure analysis of fracturing initiation of multiple radial holes and the theory of plasticity district, the criteria of multiple radial wells orientating directional fracture propagation in the condition of ground stress are derived in this study. Multiple radial well fracturing will produce a complex stress field, which guarantees to form the fracture interconnecting the radial wells and to form the main crack along the axial direction of the radial wells [22].

According to the available research results, the technology of radial borehole fracturing shows several advantages as follows:

(i) The diameter of the radial borehole is small, so it is suitable for the development of thin interbed

(ii) The radial borehole is capable of guiding the directional fracture initiation and reducing fracture initiation pressure, and the fractures can propagate directionally under some conditions (iii) The multiradial borehole fracturing creates major fractures, significantly increasing the drainage area and improving the reservoir production

(iv) Compared with the horizontal well, the radial borehole has less requirements in terms of the treatment scale, time and cost, small treatment scale, short time, and low cost and hence causes small damage to the reservoir

The fracture morphology and propagation rule during radial borehole fracturing are still not clearly defined, and there is no systematic theoretical support, especially for multiradial boreholes. Based on the actual reservoir parameters from the target well in Shengli Oil Field and considering the fluid-solid coupling effect, the 3D geological model is established with the extended finite element method (XFEM) in ABAQUS, and the fracture morphologies in the multiradial boreholes are defined. The simulation is verified by triaxial rock mechanics test experiment. Based on this, the scheme of radial bore arrangement hole is optimized, providing theoretical basis for radial borehole fracturing and showing practical importance. Also, the accuracy of arrangement optimization is verified by productivity simulation from CMG. At last, the morphology of fracture and the mechanism of fracture propagation are revealed; the radial bore arrangement hole is optimized. The technical system of radial borehole fracturing is established preliminary.

\section{Fracture Morphology and Arrangement of Radial Borehole Fracturing Based on XFEM}

\subsection{Establishment of a Radial Borehole Fracturing Model}

2.1.1. The Mechanism of a Model Based on XFEM. The core concept of extended finite element method (XFEM) is to introduce the additional function to improve the displacement space of a unit, e.g., using asymptotic function and discontinuous function to characterize the fracture tip, which ensures good simulation of fracture tip morphology and enhances the computational accuracy of grid.

In this paper, ABAQUS XFEM platform adopts the linear elastic traction-separation model and the compound fracture propagation morphology. In the model, the process of material damage is simulated with initiation and evolution stages. When the material meets the damage initiation criteria, the fracture will propagate according to the evolution rule. In this paper, the maximum principal stress (MAXPS) is applied as the criterion of judging the material damage initiation and implying that the damage occurs when the maximum principal stress of material exceeds a certain critical value. MAXPS is expressed as

$$
f=\left\{\frac{\left\langle\sigma_{\max }\right\rangle}{\sigma_{\max }^{0}}\right\}=1,
$$

which indicates that the compressive stress will not cause the damage. 
After damage initiation, the material damage evolution is based on the criterion of maximum energy release rate, with an assumption of the fracture with a length occurring in a slab of infinite unit thickness. The formula of fracture strain energy is expressed as

$$
V_{\varepsilon}=-\frac{\sigma^{2}}{2 E_{\mathrm{s}}} \pi a^{2}
$$

where $E_{\mathrm{s}}$ is the surface energy of fracture.

Fracture propagation distance $\boldsymbol{a}$ should meet the condition as follows:

$$
\left\{\begin{array}{l}
\frac{\partial\left(V_{\varepsilon}+E_{\mathrm{s}}\right)}{\partial a}=0 \\
E_{\mathrm{s}}=2 \gamma a
\end{array}\right.
$$

where $\gamma$ is the surface energy of unit area.

Formula (3) means that if the driving force of fracture propagation equals to the resistance of fracture propagation, the critical value of driving force can be derived with Formula (3), and the surface energy is replaced with the critical strain energy release rate $G_{C}$ in the lithological material.

ABAQUS provides three methods of calculating the maximum energy release rate, including the BK law, Power law, and Reeder law, among which the BK law is used in this paper to calculate the maximum energy release rate and is expressed as

$$
G_{\text {equivC }}=G_{I C}+\left(G_{I I C}-G_{I C}\right)\left(\frac{G_{I I I}+G_{I I}}{G_{I I I}+G_{I I}+G_{I}}\right)^{n}
$$

where $G_{\text {equivC }}$ is the critical fracturing energy release rate, $\mathrm{N} / \mathrm{mm}$, and when the energy release rate in the fracture tip exceeds this value, the fracture tip cracks and the fracture propagates. $G_{I C}$ and $G_{I I C}$ represent the fracturing toughness in the normal and first tangential direction, N/mm; $G_{I}, G_{I I}$, and $G_{I I I}$ represent the fracture energy release rate in the normal, first tangential, and second tangential direction, $\mathrm{N} / \mathrm{mm} ; n$ is the work of each stress in the corresponding displacement.

Here, the criteria of fracture initiation (maximum principal stress) and propagation (maximum energy release rate) are established, and the damage mechanism of the model is defined [23].

The variation of effective stress in the formation porous media will change the permeability and porosity; hence, the coupling relationship between formation stress field and porous flow field should be considered. According to the virtual work principle, the stress equilibrium equation is expressed as

$$
\int_{V} \sigma \delta \varepsilon d V=\int_{S} t \delta v d S+\int_{V} \widehat{f} \delta v d V
$$

where $\delta v$ is the virtual velocity, $\mathrm{m} / \mathrm{s} ; \delta \varepsilon$ is the virtual strain rate, $\mathrm{s}^{-1} ; f$ is the body force of unit volume, $\mathrm{N} / \mathrm{m}^{3}$; $t$ is the surface external force of unit area, $\mathrm{N} / \mathrm{m}^{2}$; and $\sigma$ represents the total stress of porous medium, $\mathrm{Pa}$.

According to the principle of mass conservation, the continuity equation of a fluid medium is expressed as

$$
\int_{V} \delta v \frac{1}{J} \frac{d}{d t}\left(J \rho_{w} n_{w}\right) d V+\int_{V} \delta v \frac{\partial}{\partial x}\left(\rho_{w} n_{w} v_{w}\right) d V=0
$$

where $J$ is the variation rate of pore volume; $n_{w}$ is the ratio of formation liquid volume to total pore formation volume; $\rho_{w}$ is the liquid density in the pore, $\mathrm{kg} / \mathrm{m}^{3} ; x$ is the direction vector of fluid flow in the pore, $\mathrm{m}$; and $v_{w}$ is the liquid flow velocity in the pore, $\mathrm{m} / \mathrm{s}$.

The relationship between liquid velocity of seepage flow and the gradient pressure in a porous medium could be expressed by Darcy's formula:

$$
v_{w}=-\frac{1}{n_{w} g \rho_{w}} k\left(\rho_{w}-\rho_{w} g\right)
$$

where $k$ is the hydraulic conductivity tensor and $g$ is the gravity acceleration vector.

The conditions of a porous medium are defined with the simultaneous equations of Formulas (5) and (6). By integrating the equation set and the boundary conditions, the equilibrium and the continuity equations can be approximately expressed as the finite element equation set with interpolation function introduced in the finite element discretization. The stress-flow coupling equation matrix is eventually established and is resolved with the Newton method in ABAQUS.

Here, a model considering multiple factors such as geostress and rock mechanics properties is established by combining XFEM in ABAQUS with fluid-solid coupling, in which the criterion of maximum principal stress is applied to determine the position of rock fracture (fracture initiation), the criterion of maximum energy release rate is applied to judge the fracture damage evolution (fracture propagation morphology), and the fracture propagation in the radial borehole fracturing is studied [24]. The simulation provides a real and visual result, with the reference and guidance value.

2.1.2. Establishment and Validation of a Model. The model assumes that the direction of $X$ axis is consistent with that of the horizontal maximum principal stress with $0^{\circ}$ azimuth, and the azimuth increases in the anticlockwise direction with borehole as the center; the intersection angle $\theta$ between radial borehole and horizontal maximum principal stress is defined as the radial borehole azimuth (the radial borehole with minimum $\theta$ is considered as the reference well in case of multiradial borehole). $Z$ axis is defined as the direction of vertical stress. The unit of stress is $\mathrm{kPa}$, and the tensile stress is positive in the model.

The basic models of single radial borehole, horizontal multiradial borehole, and vertical multiradial borehole (Figure 1) are established, and the fracture propagation is simulated with XFEM to obtain the fracture morphology under different parameters. The intersection angle between two radial boreholes in the same layer is defined as the phase 

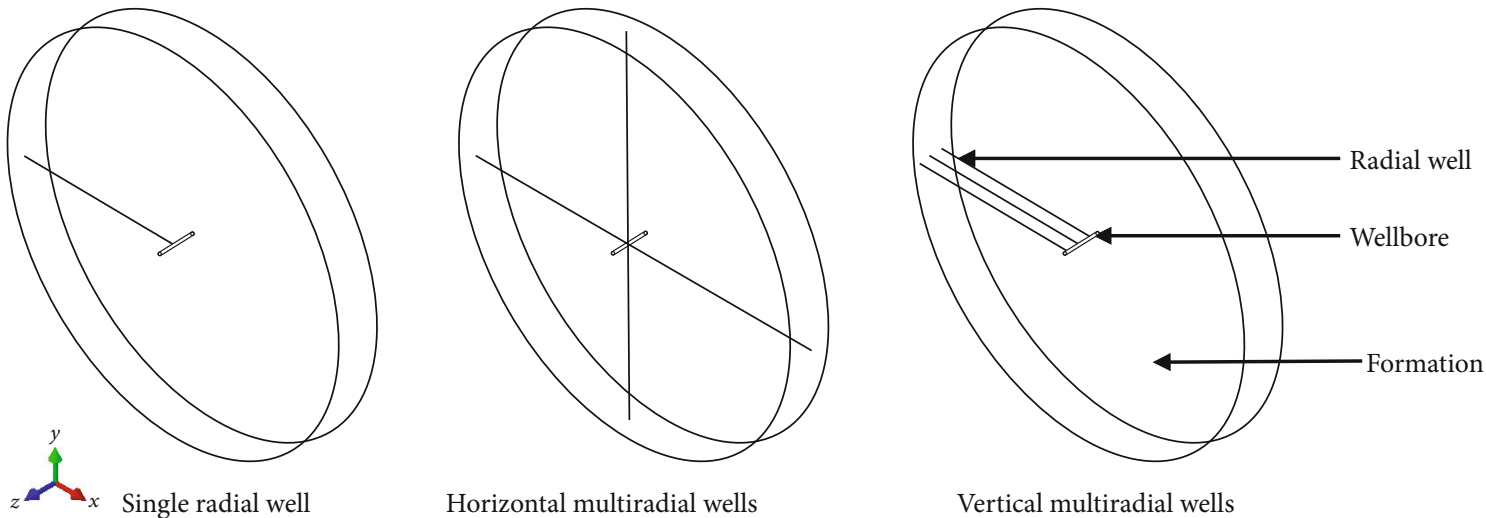

Horizontal multiradial wells

Vertical multiradial wells

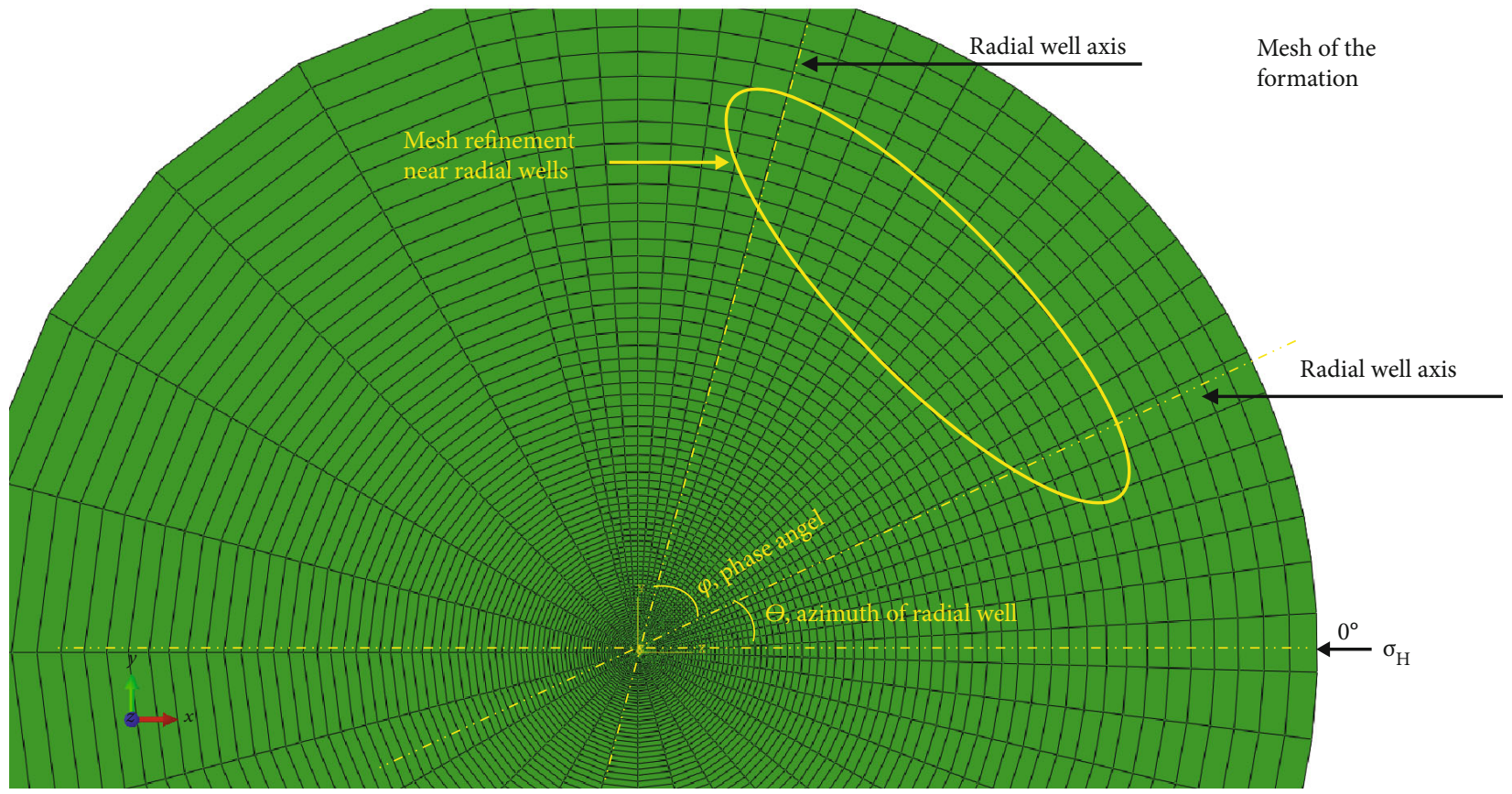

FIgURe 1: Sketch of a model.

TABLE 1: Table of hydraulic fracturing model data.

\begin{tabular}{lccccc}
\hline Elasticity modulus $(\mathrm{GPa})$ & Poisson's ratio & $\begin{array}{l}\text { Horizontal maximum } \\
\text { principal stress }(\mathrm{MPa})\end{array}$ & $\begin{array}{c}\text { Horizontal minimum } \\
\text { principal stress }(\mathrm{MPa})\end{array}$ & $\begin{array}{c}\text { Porosity (\%) } \\
\text { prisplacement in the }\end{array}$ & $\begin{array}{c}\text { Disperiment (ml/min) } \\
\text { experimer }\end{array}$ \\
\hline 16.14 & 0.18 & 15 & 9 & 12 & 100 \\
\hline
\end{tabular}

angle $\varphi$. About 10,000 elements are generated in the model, and the type of element is structured.

The XFEM numerical model in the radial borehole fracturing is validated with the laboratory large-scale true triaxial hydraulic fracturing physical simulation experiment, where a large-scale true triaxial fracturing simulation system capable of simultaneously imposing horizontal maximum principal stress, horizontal minimum principal stress, and vertical stress is adopted. The test specimen is made with appropriate proportion of cement and silica sand, so the mechanical parameters of specimen are consistent with those of numerical simulation. The simulated wellbore is placed in the center of specimen, and the radial borehole is preset. The fresh water added with red tracer is used as the fracturing fluid. The physical simulation system mainly simulates the value and distribution of geostress in the formation. The experimental conditions and rock parameters are listed in Table 1. The experiment is conducted with steps in the reference.

With horizontal stress difference being $6 \mathrm{MPa}$ and azimuth being $30^{\circ}$, the fracture propagates along the radial borehole, but the fracture distortion and diversion occur in the fracture plane. At this moment, the single radial borehole has limited guidance to fracture propagation. When increasing the vertical radial borehole density, the fracture plane propagates along the radial borehole direction and the 

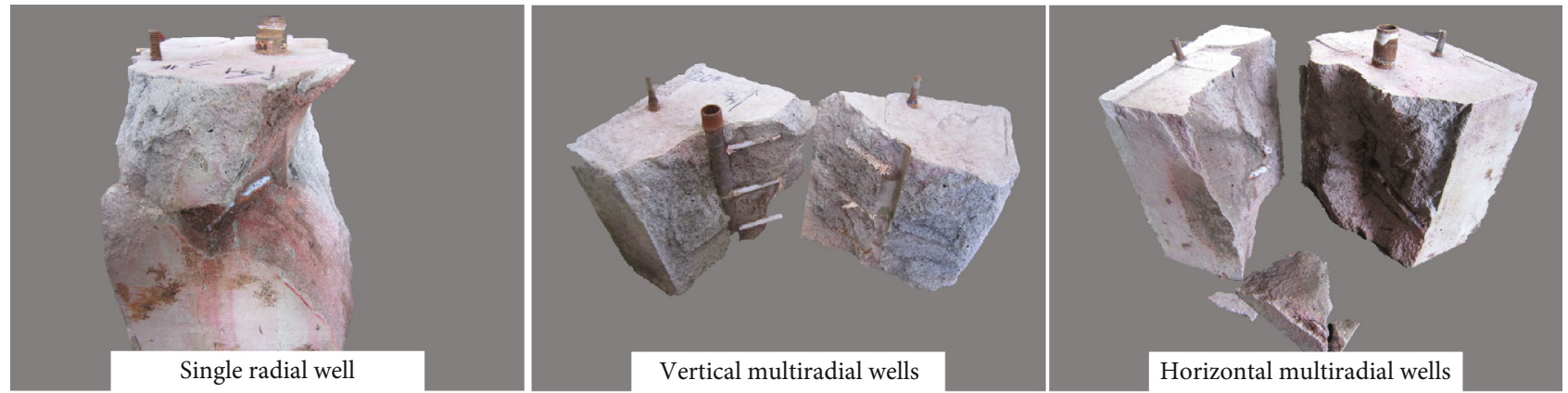

$S$, Max. principal
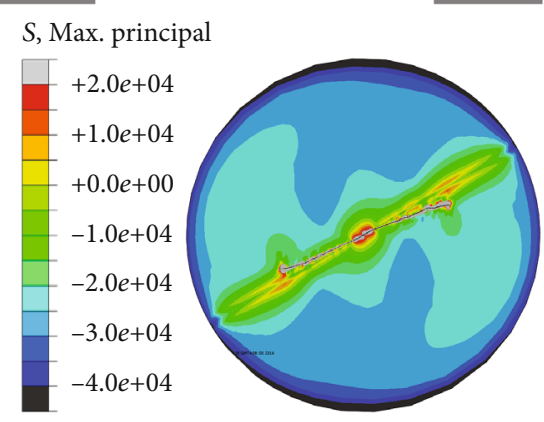

$S$, Max. principal
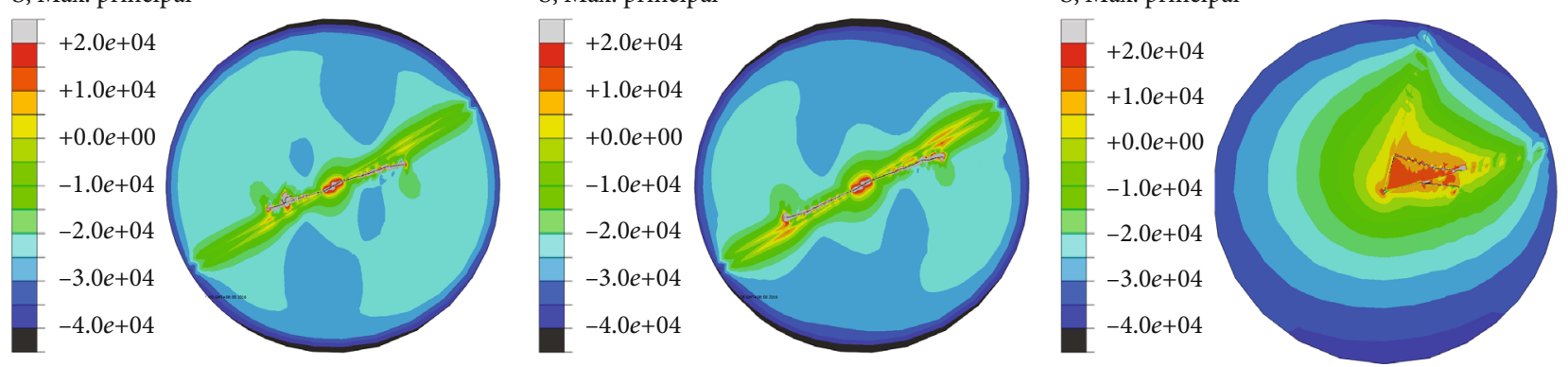

FIGURE 2: Comparison of simulation results and experiment results.

TABLE 2: Table of basic model parameters.

\begin{tabular}{lcccc}
\hline Well hole diameter $(\mathrm{mm})$ & 240 & Formation elasticity modulus (GPa) & 20 & 3 \\
Formation diameter $(\mathrm{m})$ & 150 & Rock tensile strength (MPa) & 15 \\
Formation thickness (m) & 0.2 & Pore pressure (MPa) & 35 \\
Radial bore diameter (mm) & 50 & Vertical pressure (MPa) & 33.33 \\
Radial bore length (m) & 75 & Horizontal maximum principal stress (MPa) & 32.45 & 34.18 \\
Porosity (\%) & 25 & Horizontal minimum principal stress (MPa) & 26.43 & 25.33 \\
& & Horizontal stress difference (MPa) & 6 & 8 \\
\hline
\end{tabular}

fracture has a flat profile; thus, the radial borehole has strong guidance to fracture propagation under conditions of vertical multiradial borehole. The near-well-bore fracture under horizontal multiradial boreholes firstly connects the neighboring radial boreholes and propagates, and there is no major fracture propagating along the radial borehole, which is limited by the size of physical simulation. The result of physical experiment tends to be consistent with that of numerical simulation (Figure 2), indicating a certain level of reliability of fracture dynamic propagation simulation by XFEM, which is applicable in the research on fracture propagation dynamics of radial borehole fracturing.

Based on the actual reservoir parameters, the application parameters of the formation basic model are created and shown in Table 2.

When applying XFEM to simulate the hydraulic fracture propagation, the propagation trajectory is represented in an irregular and circuitous form. The irregular and circuitous path of fracture makes it hard to analyze the simulation results quantitatively which is adverse to reveal and evaluate the mechanism and effect of radial borehole fracturing. Therefore, the concept of "equivalent hydraulic fracture" is introduced for the sake of study. As shown in Figure 3, the circular boundary is established with the same radial borehole length $R$ as the radius, and the area confined by hydraulic fracture, radial borehole, and circular boundary is defined as $S$. A straight equivalent hydraulic fracture is established, and the area confined by hydraulic fracture and circular boundary (radius $R$ ) is $S_{\text {eq }}=S$. Then, the intersection angle between equivalent hydraulic fracture and radial borehole is defined as the equivalent fracture deflection angle $\eta$, and the smaller the $\eta$, the stronger the radial borehole's guidance is to hydraulic fracture directional propagation.

\subsection{Numerical Simulation and Analysis of Single Radial Borehole Fracturing}

2.2.1. Fracture Morphology of Single Radial Borehole Fracturing. Simulation with horizontal stress difference $6 \mathrm{MPa}$, perforation (drilling) azimuth $45^{\circ}$, radial borehole fracturing $\eta=4^{\circ}$, and directional perforation fracturing $\eta=30^{\circ}$ and conventional perforation fracturing $\eta=45^{\circ}$ show that the radial borehole fracturing is capable of guiding 


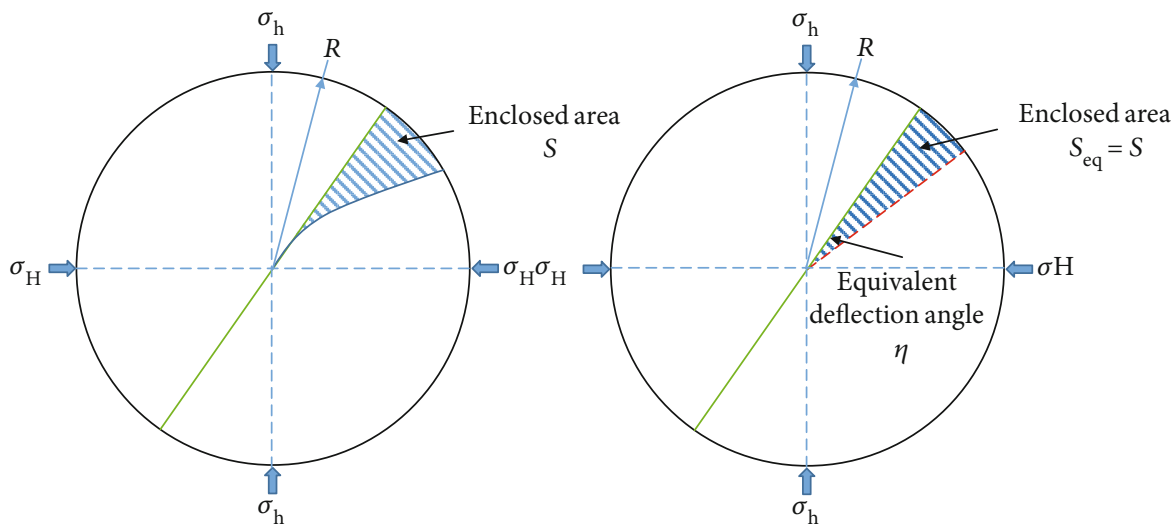

$\begin{array}{ll}\text { Radial well } & --- \text { Equivalent fracture } \\ \text { _ Real fracture } \quad \text { Ev Enclosed area }\end{array}$

FIGURE 3: Sketch of equivalent fracture.

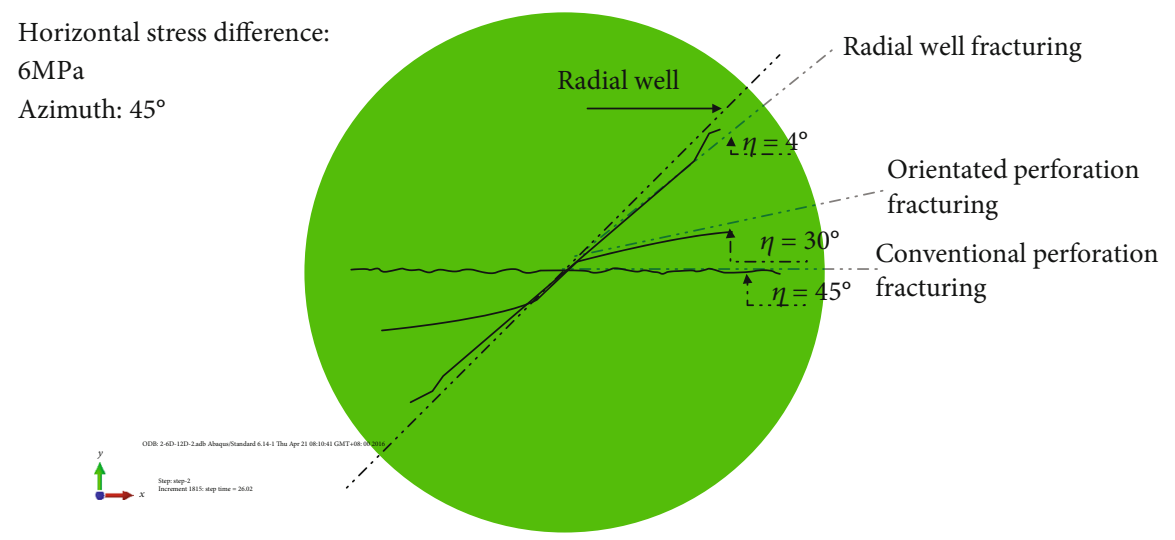

FIGURE 4: Simulation results of different fracture type.
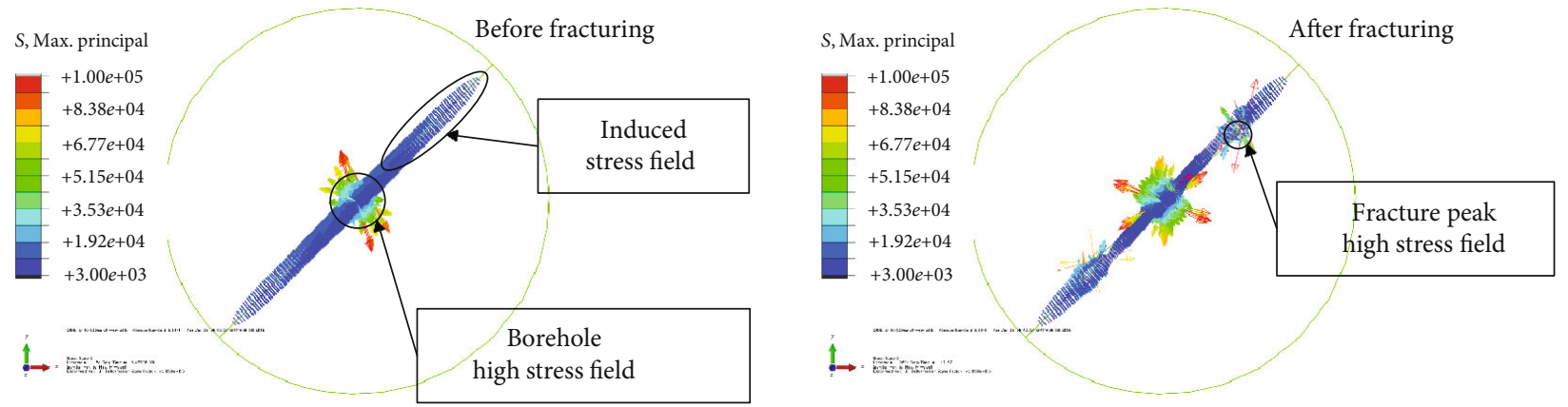

FIgURE 5: Stress direction diagram of induced stress field.

fracture directional propagation and is conductive to directional development of the remaining oil and enhancing oil recovery (Figure 4).

Taking the condition of horizontal stress difference being $6 \mathrm{MPa}$ and radial borehole azimuth being $45^{\circ}$ as an example, the fracturing fluids flow through radial borehole into the formation, forming an induced stress field along the radial borehole. The induced stress within the field can change the value and direction of the original geostress within limits, forming the horizontal tensile stress perpendicular to the radial borehole axis (Figure 5). This tensile stress is the primary cause of fracture directional propagation guided by the radial borehole [25]. Fracture propagation shows tendency of diversion to the horizontal maximum principal stress. The fracture diversion caused by the original geostress is weakened by the induced stress. Affected by both original geostress and induced stress, the fracture propagates with an intersectional angle with radial borehole. As the fracture 


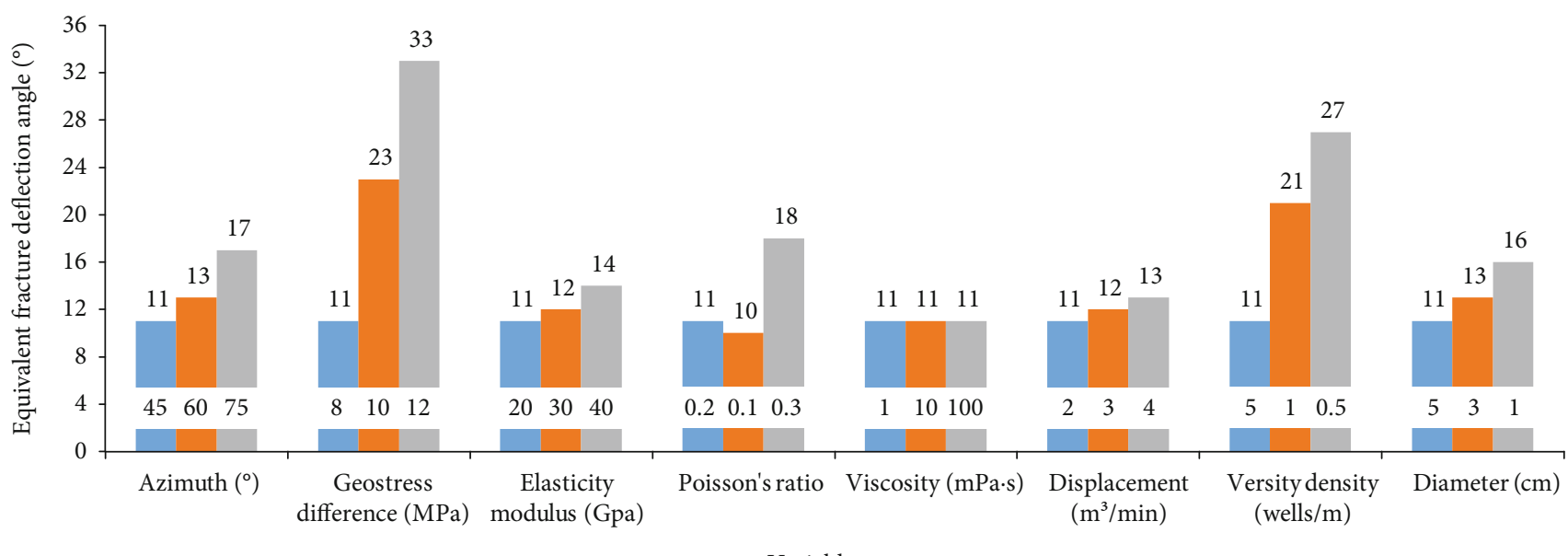

Variable type

Control group

Experimental group 1

Experimental group 2

(a) Influence of parameters on equivalent fracture deflection angle

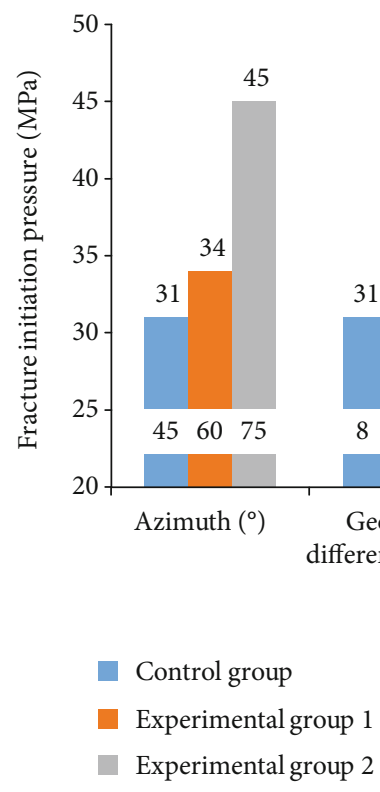

(b) Influence of parameters on fracture initiation pressure

Figure 6: Analysis of simulation result.

further propagates and breaks away from the induced stress field, it is deflected to the direction of horizontal maximum principal stress under the influence of the original geostress. Figure 5 shows that the effective guiding distance of radial borehole to fracture directional propagation can reach $40 \mathrm{~m}$.

In the simulation with ABAQUS, "maximum principal stress (Max Principle)" is the maximum stress numerically, and it can be defined as "maximum tensile stress" or "minimum compressive stress" in the model with positive tensile stress. According to the criterion of maximum principal stress, rock failure and fracture occur when the maximum principal stress exceeds the rock tensile strength.
2.2.2. Quantitative Analysis of Parameters on Fracture Propagation. According to the definition of equivalent hydraulic fracture, the results of numerical simulation with different parameters in the single radial borehole are collected to draft the graph which is shown in Figure 6, in which the influences of different parameters on the fracture morphology are analyzed. With azimuth $45^{\circ}$, horizontal geostress difference $8 \mathrm{MPa}$, formation elasticity modulus $20 \mathrm{GPa}$, formation Poisson's ratio 0.2 , fracturing fluids viscosity $1 \mathrm{mPa} \cdot \mathrm{s}$, treatment displacement $2 \mathrm{~m}^{3} / \mathrm{min}$, vertical density of radial borehole 5 wells $/ \mathrm{m}$, and radial borehole diameter $5 \mathrm{~cm}$ as the control group, control variable analysis is conducted. The variables of the experimental group include azimuths 
TABLE 3: Correlation results.

\begin{tabular}{|c|c|c|c|c|c|c|c|c|}
\hline Factors & $\begin{array}{c}\text { Radial } \\
\text { borehole } \\
\text { azimuth }\end{array}$ & $\begin{array}{l}\text { Horizontal } \\
\text { stress } \\
\text { difference }\end{array}$ & $\begin{array}{l}\text { Elasticity } \\
\text { modulus }\end{array}$ & $\begin{array}{l}\text { Poisson's } \\
\text { ratio }\end{array}$ & $\begin{array}{c}\text { Fracturing } \\
\text { fluid } \\
\text { viscosity }\end{array}$ & $\begin{array}{c}\text { Fracturing } \\
\text { displacement }\end{array}$ & $\begin{array}{c}\text { Vertical } \\
\text { density of } \\
\text { radial hole }\end{array}$ & $\begin{array}{c}\text { Radial } \\
\text { borehole } \\
\text { diameter }\end{array}$ \\
\hline$\eta$ value & 0.7544 & 0.8320 & 0.7451 & 0.7420 & I & 0.7482 & 0.8095 & 0.7095 \\
\hline $\begin{array}{l}\text { Fracture initiation } \\
\text { pressure }\end{array}$ & 0.8158 & 0.7728 & 0.7582 & 0.7498 & 0.7743 & 0.7765 & 0.8361 & 0.7433 \\
\hline
\end{tabular}

$60^{\circ}$ and $75^{\circ}$, horizontal geostress differences $10 \mathrm{MPa}$ and $12 \mathrm{MPa}$, formation elastic moduli $30 \mathrm{GPa}$ and $40 \mathrm{GPa}$, formation Poisson's ratios 0.1 and 0.3 , fracturing fluid viscosity $10 \mathrm{mPa} \cdot \mathrm{s}$ and $100 \mathrm{mPa} \cdot \mathrm{s}$, treatment displacement $3 \mathrm{~m}^{3} / \mathrm{min}$ and $4 \mathrm{~m}^{3} / \mathrm{min}$, vertical density of radial borehole 1 well $/ \mathrm{m}$ and $0.5 \mathrm{well} / \mathrm{m}$, and radial borehole diameters $3 \mathrm{~cm}$ and $1 \mathrm{~cm}$.

Figure 6 shows that as the azimuth increases, the fracture initiation pressure gradually increases. Thus, the equivalent fracture deflection angle increases as the azimuth increases; the equivalent fracture deflection angle increases significantly as the horizontal geostress difference increases. The increase of the radial borehole diameter benefits radial borehole fracturing, but the increase of the azimuth, horizontal geostress difference, reservoir thickness, formation elasticity modulus, Poisson's ratio, and treatment displacement is not favorable to radial borehole fracturing.

The results of numerical simulation indicate that different horizontal geostress difference, radial borehole azimuth, rock elastic modulus, Poisson's ratio, fracturing fluid viscosity, treatment displacement, radial borehole vertical density (calculated according to reservoir thickness), and radial borehole diameter all have an influence on the $\eta$ value and fracture initiation pressure or maximum fracture width. Limited by data volume, the grey correlation analysis can be adopted to determine the influences of those factors on study object, providing reference for optimization of radial borehole fracturing.

After the collection and calculation of the original data from experiment [26], the correlations of $\eta$ and fracture initiation pressure can be obtained, as shown in Table 3.

According to Table 3, based on correlation, factors affecting $\eta$ value are ranked from high to low as follows: horizontal stress difference, radial borehole vertical density, fracturing fluid viscosity, radial borehole azimuth, reservoir Poisson's ratio, reservoir elastic modulus, fracturing displacement, and radial borehole diameter. The factor of fracturing fluid viscosity is deleted because the $\eta$ value is constant in the variation of viscosity.

Based on correlation, factors affecting fracturing initiation pressure are ranked from high to low as follows: radial borehole vertical density, radial borehole azimuth, fracturing displacement, fracturing fluid viscosity, horizontal stress difference, reservoir elasticity modulus, reservoir Poisson's ratio, and radial borehole diameter.

Thus, by increasing radial borehole vertical density, guidance of radial borehole to the hydraulic fracture can be effectively enhanced, and among human factors, the radial borehole vertical density accounts for the greatest weight. In this regard, an appropriate well density is of great impor- tance. Selection of radial borehole azimuth exerts the greatest influence on the fracture initiation pressure, so an appropriate azimuth can help reduce the difficulty in fracturing treatment and increase the success rate of fracturing.

2.3. Numerical Simulation and Analysis of Multiradial Borehole Fracturing. The existing studies show that both single radial borehole and vertical multiradial borehole, which follow the same rules of fracture initiation $[10,14]$, can cause fracture directional initiation (fracture initiated in the radial borehole), with the fracture initiation effect as the only difference. However, the fracture propagation morphology should be further studied.

\subsubsection{Fracture Morphology of Multiradial Borehole} Fracturing. The existing study shows that the geostress of multiradial borehole is the superimposition of that of single radial borehole [27]. Thus, the fracture propagation mechanism in the horizontal dual-radial borehole is studied to represent the multiradial boreholes in this paper. As shown in Figure 7 , there is an induced stress field along each radial borehole in the distant area of horizontal multiradial borehole. Due to the influence of main vertical borehole and radial borehole, there is a complex stress field, which has high value and complex distribution. Then, this stress field is defined as the interference stress field. Obviously, the fracture initiation occurs earlier in the interference stress field near wellbore than in the induced stress field in the distant area.

(1) Fracture Propagation in the Interfered Stress Field. A thirty-meter diameter reservoir geological model based on the data in Table 2 is established to research the distribution of interference stress field and fracture morphology in the near-borehole zone.

The fracture morphology is analyzed in the model with azimuth of $30^{\circ}$, phase angle of $45^{\circ}$, and horizontal stress difference of $6 \mathrm{MPa}$. According to the result of simulation (Figure 8), the interference stress field is divided into two parts. The first part is the stress field resulting from interference of dual-radial borehole and vertical borehole, as shown in the area marked by yellow solid line. The stress in the field has a high value, and its direction is complex and irregular. Thus, a fracture is firstly initiated in the near-borehole zone, where an area of high stress exists, and simultaneous fracture initiation and multifracture can possibly occur. The second part is the stress field resulting from interference of dualradial borehole, as shown in the area marked by yellow dashed line, but this area is not influenced by the borehole 

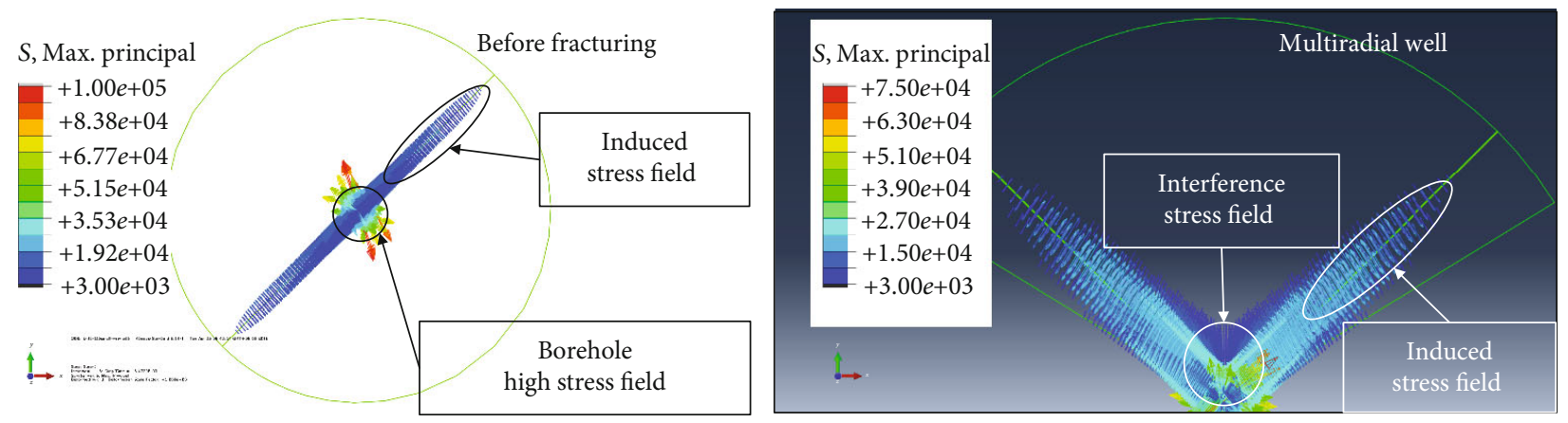

FigURE 7: Simulation results of induced stress field and interference stress field.
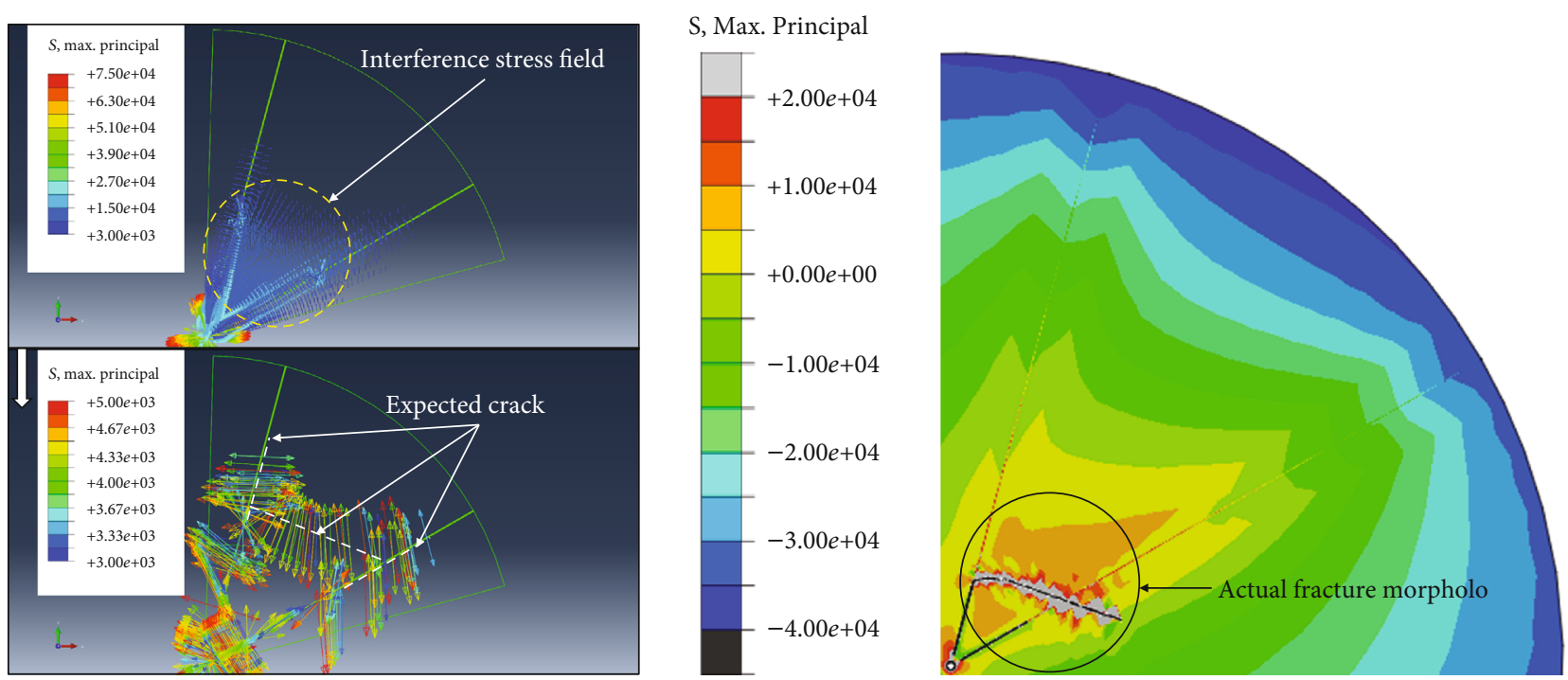

FIGURE 8: Fracture morphology in interference stress field.

stress. The tensile stress perpendicular to the line connecting both radial boreholes is generated inside the stress field. Thus, a secondary fracture connecting both radial boreholes is formed (principal fracture propagated along the well), as shown in white dashed line. According to the simulation, the actual propagation trajectory of the secondary fracture is consistent with the result of the previous analysis, and the secondary fracture possibly further propagates after connecting both radial boreholes.

As the phase angle increases, the influence of interference stress field on the fracture morphology is gradually weakened. As the phase angle reaches $90^{\circ}$, the possibility of generating a secondary fracture connecting dual radial boreholes in the interference stress field is low. Thus, when the phase angle of dual-radial borehole exceeds $90^{\circ}$, it is considered that the influence of the interference of dual-radial borehole on the fracture propagation is weak, which is negligible (Figure 9).

(2) Fracture Propagation in the Induced Stress Field. The fracture is analyzed in the model (formation diameter $150 \mathrm{~m}$ ) with a phase angle of $90^{\circ}$ and horizontal stress difference of $6 \mathrm{MPa}$. According to the simulation result (Figure 10), the principal fracture in the distant area propagates individually along the corresponding radial borehole, with the same propagation rule as that in the single-radial borehole fracturing [28]. Because of the difference of the fracture initiation pressure in the dual-radial borehole fracturing, the fracture is firstly initiated in the radial borehole near the maximum principal stress, where the fracture propagation distance is further.

In conclusion, affected by the interference of dual-radial borehole, the fracture is firstly initiated in the interference stress field in the near-borehole zone, and then the secondary fracture connecting the dual radial borehole is generated. The complex multifractures are possibly generated in the interference stress field, which can reduce the flow resistance near wellbore and decrease the pressure loss along the path. As fracturing goes on, the multiple principal fractures propagating along each radial borehole occur in the induced stress field in the distant area, significantly increasing the drainage area and enhancing the deliverability.

2.3.2. Theoretical Analysis of Multiradial Borehole Arrangement. The fracture conductivity is not applicable in 


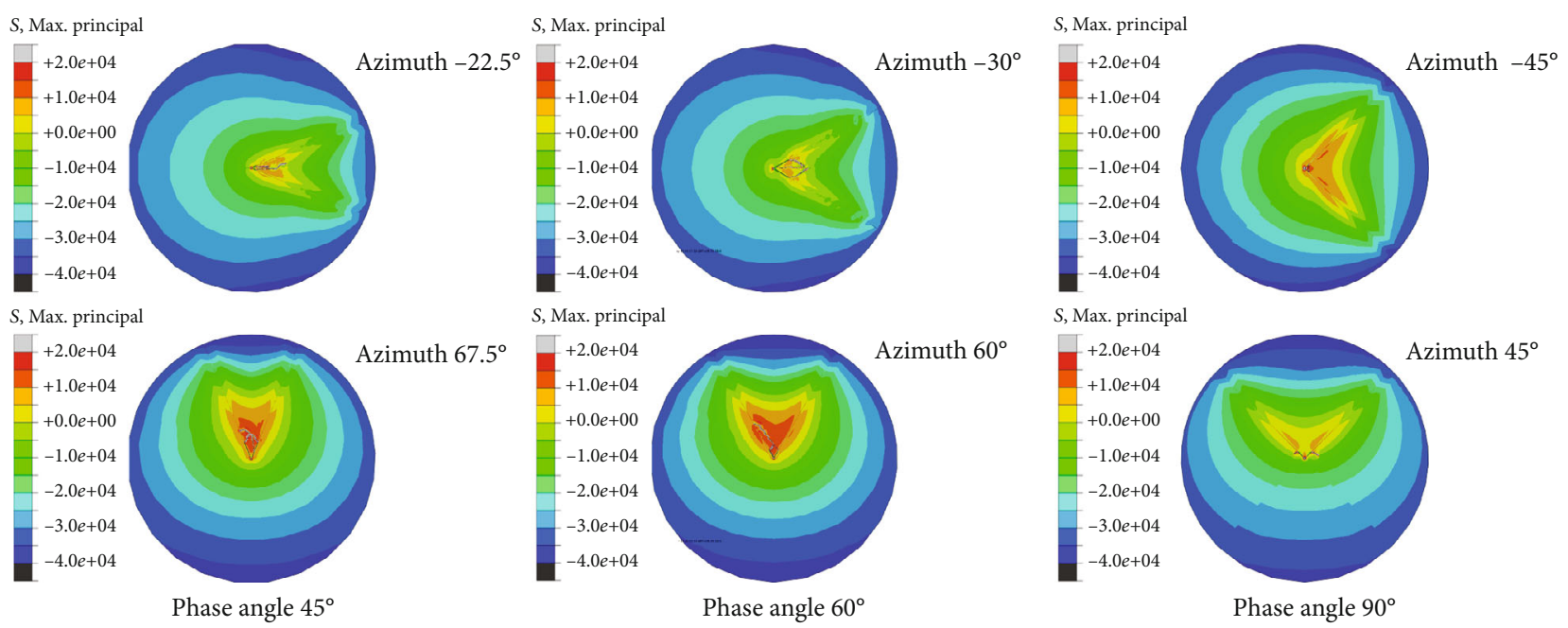

FIGURE 9: Simulation results of fracture morphology in interference stress field.
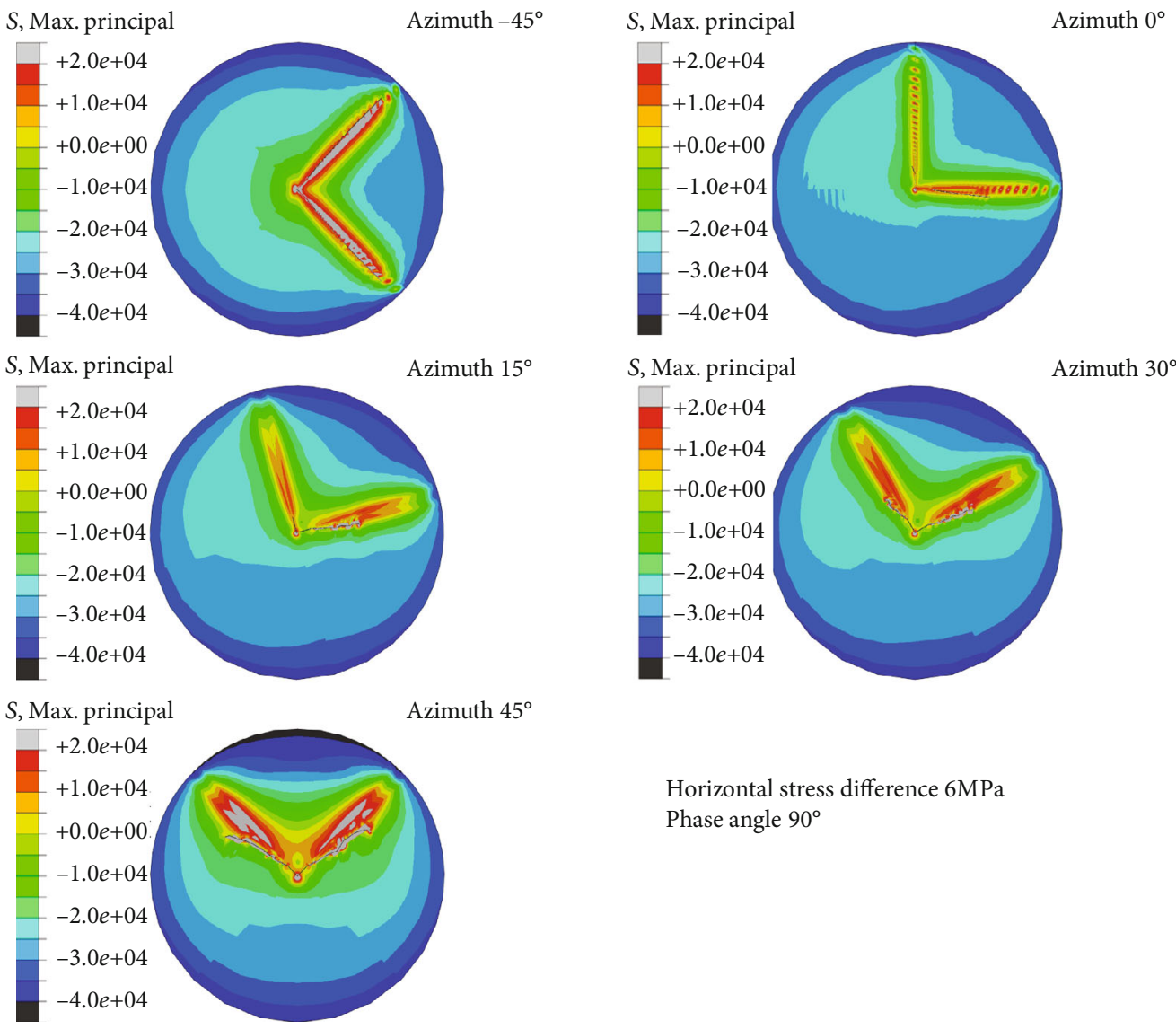

Horizontal stress difference $6 \mathrm{MPa}$ Phase angle $90^{\circ}$

FIGURE 10: Fracture morphology of two radial boreholes.

evaluating the multiple fractures generated in the multiradial borehole fracturing. Referencing evaluation of fracture network by stimulated reservoir volume in the volume fracturing, the concept of "sweep area" is put forward to evaluate the multiple fractures: it is assumed that the fracture generated by radial borehole fracturing penetrates through the reservoir with consistent fracture height, the fracture is equivalent to a line in the top-down plane of reservoir, and the effective producing range of fracture (straight line) is defined as the sweep area. The reservoir beyond the sweep area cannot be effectively produced. Thus, in order to maximize the drainage area and the reservoir deliverability, the borehole arrangement scheme should be optimized according to the maximum superimposed sweep area of fractures. 


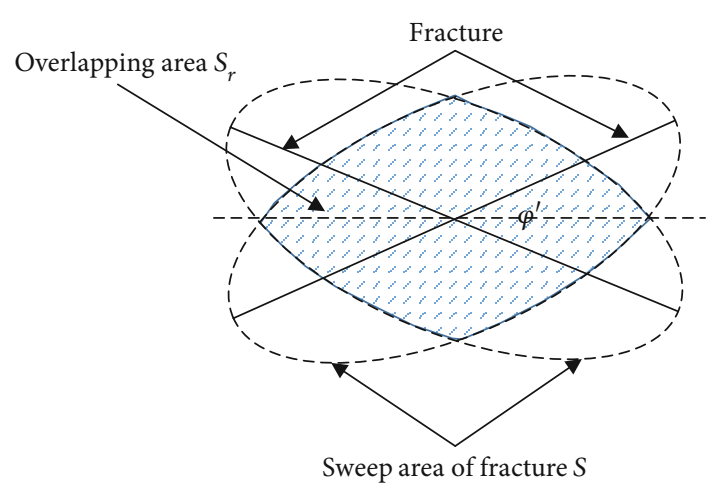

FIGURE 11: Sketch of a sweep area in oval.

The sweep area of single fracture is matched with a geometric figure, and the total sweep area of multiple principal fractures is obtained by concentric rotation of a geometric figure. In this paper, the oval is taken as an alternative of a single fracture sweep area (Figure 11), and the optimum matching effect under different reservoir and fracture parameters can be obtained through adjusting the value of major and minor axes, which is flexible and can be widely used.

The sweep area of multifractures in the multiborehole (assume $n$ radial boreholes and hydraulic fractures propagating along the radial borehole, i.e., superimposition of fractures and radial borehole) is the sum of each figure area minus the superimposed area $\left(S_{e}=n S-(n-1) S_{r}\right)$. The formula $S_{e}=f(\varphi)$ is about total sweep area in regard to $\varphi$ with known reservoir and fracture properties. The optimum fracture phase angle $\varphi=360^{\circ} / n$ corresponding to the maximum sweep area is obtained through analytical geometry.

In summary, according to the multiple fracture morphology and the sweep area, two principles of optimizing borehole arrangement scheme in the homogeneous reservoir are obtained as follows: the radial boreholes are symmetrically arranged along the horizontal maximum principal stress; the radial boreholes are uniformly distributed in the horizontal plane.

\section{Verification of Multiradial Borehole Arrangement Based on Deliverability}

In order to verify the theoretical analysis of multiradial borehole arrangement, the numerical simulation based on deliverability is arranged. Obviously, the highest productivity indicates the optimized multiradial borehole arrangement.

According to actual geological conditions of reservoir, a conceptual model is established in CMG, and the influences of parameters on the deliverability in different development schemes are analyzed. An edge-water-driven model in the Cartesian coordinate system is established in CMG, with a size of $25^{*} 25^{*} 5(I, J$, and $K$ ) and step size of $10 \mathrm{~m}$ in $I$ and $J$ direction. The rock and fluid parameters are valued according to actual reservoir parameters, e.g., original reservoir pressure $15.6 \mathrm{MPa}$, effective pay thickness $10 \mathrm{~m}$, formation temperature $75^{\circ} \mathrm{C}$, formation pore pressure coefficient 1.02, underground oil viscosity $12,282 \mathrm{mPa} \cdot \mathrm{s}$, and oil density
$0.98 \mathrm{~g} / \mathrm{cm}^{3}$, as shown in Table 2 . The relative permeability curves of oil and water are displayed in Figure 12.

According to the existing studies and above research, the guidance of radial borehole to hydraulic fracture reaches the effective distance of $40 \mathrm{~m}$. The designed semifracture length in the actual fracturing treatment is $40 \mathrm{~m}$. Thus, the semifracture length in the model is $40 \mathrm{~m}$. Referencing the concept of "equivalent fracture," the fracture with a straight shape is inserted into the reservoir. The fracture conductivity is chosen as $80 \mu \mathrm{m}^{2} \cdot \mathrm{cm}$, the designed value in the actual fracturing plan [29].

As the radial borehole deliverability accounts for a small proportion of total deliverability of radial borehole-assisted fracturing [21], the deliverability of radial borehole is negligible in the numerical simulation with CMG.

\subsection{Simulation and Analysis on Deliverability under Different} Fracture Parameters. The morphology of four fractures generated during four radial borehole fracturing is chosen as the basic template for the study, as shown in Figure 13. Changing the equivalent fracture phase angle, the deliverability of radial borehole fracturing is analyzed with different fracture phase angles. The fracture phase angle is $0^{\circ}$, which can be equivalent to dual fractures, i.e., there are two principal fractures (which are perpendicular to horizontal minimum principal stress) generated in the conventional fracturing.

The accumulative oil production and water cut during three years of development are shown in Figure 14. As the fracture phase angle increases, the accumulative oil production increases significantly and reaches the peak when the phase angle is $90^{\circ}$. Moreover, the larger the fracture phase angle, the earlier water breakthrough occurs, and the faster the water cut rises. Thus, in terms of increasing deliverability, the well should be produced with a fracture phase angle of $90^{\circ}$, and the water-block measure should be adopted in the late period of production to further enhance oil recovery. The conclusion is consistent with the result of optimizing the radial borehole arrangement scheme with the maximum sweep area as the standard, indicating the accuracy of the maximum sweep area method, that is, the maximum sweep area and deliverability are obtained with uniform radial borehole distribution in the plane. Thus, the method of uniform radial borehole distribution is chosen in the simulation of multiradial borehole fracturing.

Changing the number of equivalent fractures, the variation of deliverability of radial borehole fracturing under different fracture numbers is analyzed, as shown in Figure 15.

The accumulative oil production and water cut during three years of development are shown in Figure 16. The deliverability of a single well is stimulated significantly by fracturing, and the deliverability of a single fracture is doubled compared with a nonfractured well. As the number of fracture increases, the deliverability increases more slowly, and the water breakthrough advances. Meanwhile, the water cut increases with the growth of the number of fractures.

Theoretical analysis of the maximum sweep area shows that as the fracture increases (uniformly distributed in the plane), the total sweep area gradually increases, but at the same time, the fracture superimposed area also increases, so 


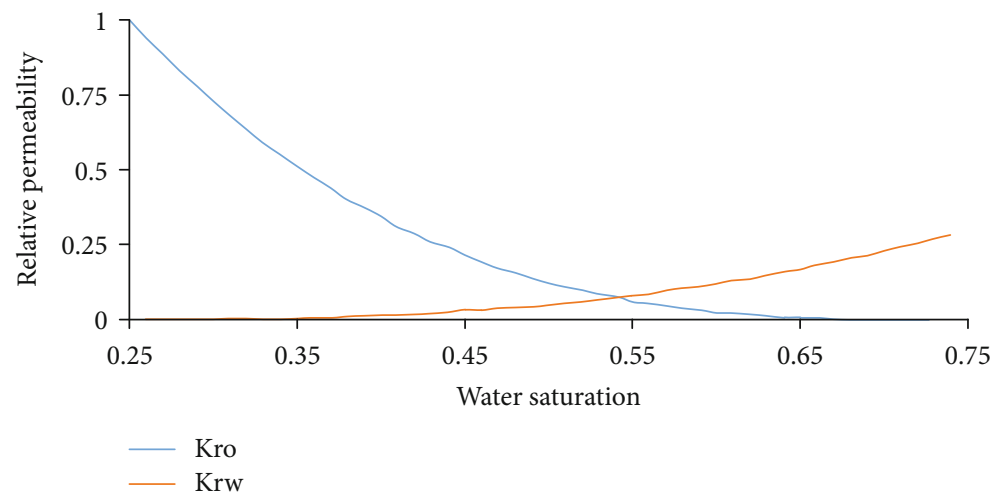

FIgURE 12: Relative curve of oil and water.

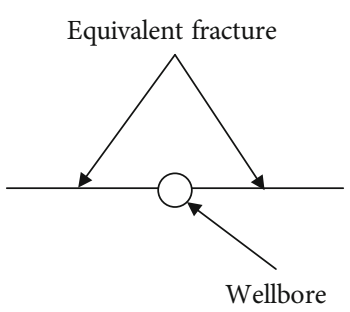

$0^{\circ}$ phase angle

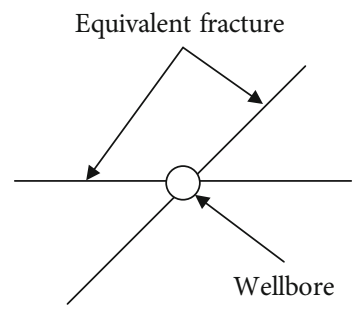

$45^{\circ}$ phase angle

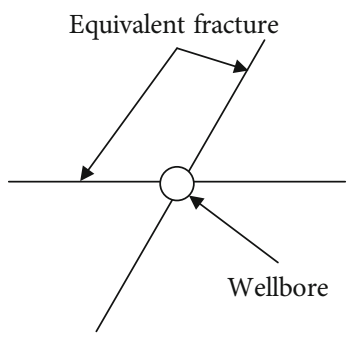

$60^{\circ}$ phase angle

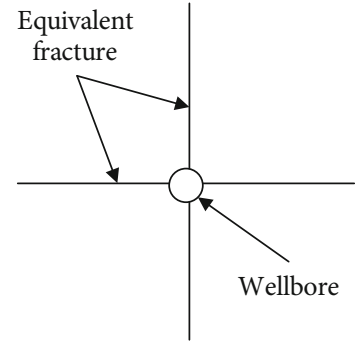

$90^{\circ}$ phase angle

FIgURE 13: Sketch of a model under different phase angle of fracture.

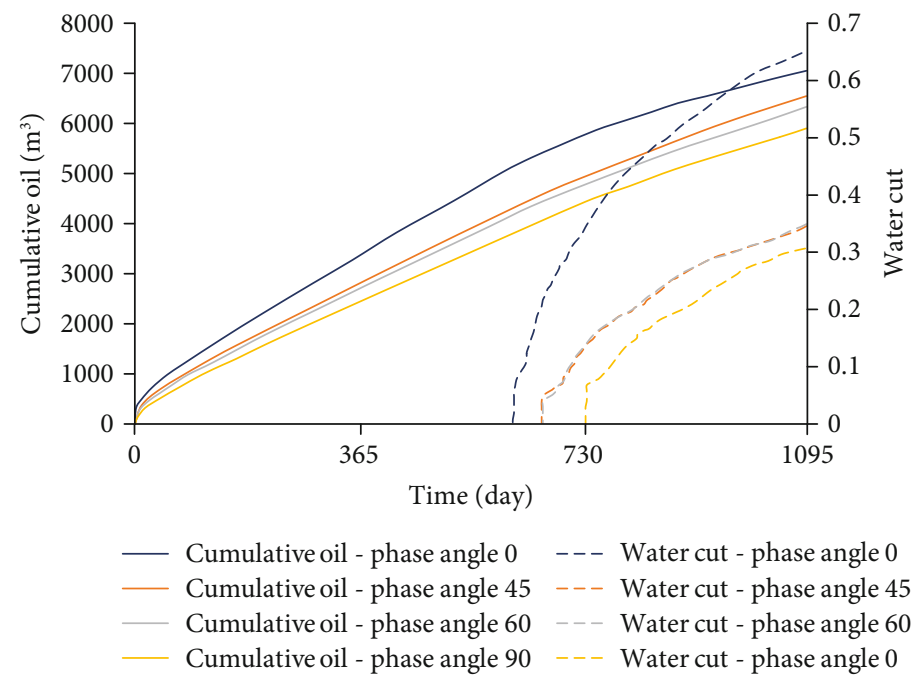

FIgURE 14: Variation of cumulative oil and water cut on the phase angle of fracture.

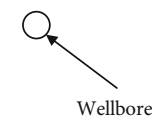

No crack

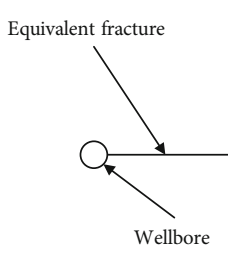

1 crack

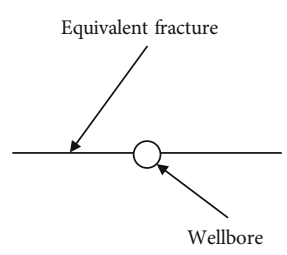

2 cracks

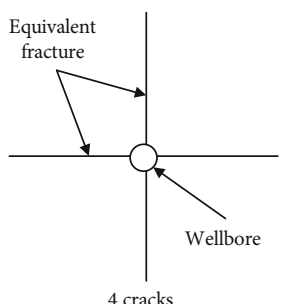

4 cracks

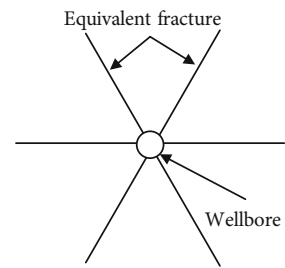

6 cracks

FIGURE 15: Sketch of a model under different amount of fracture. 


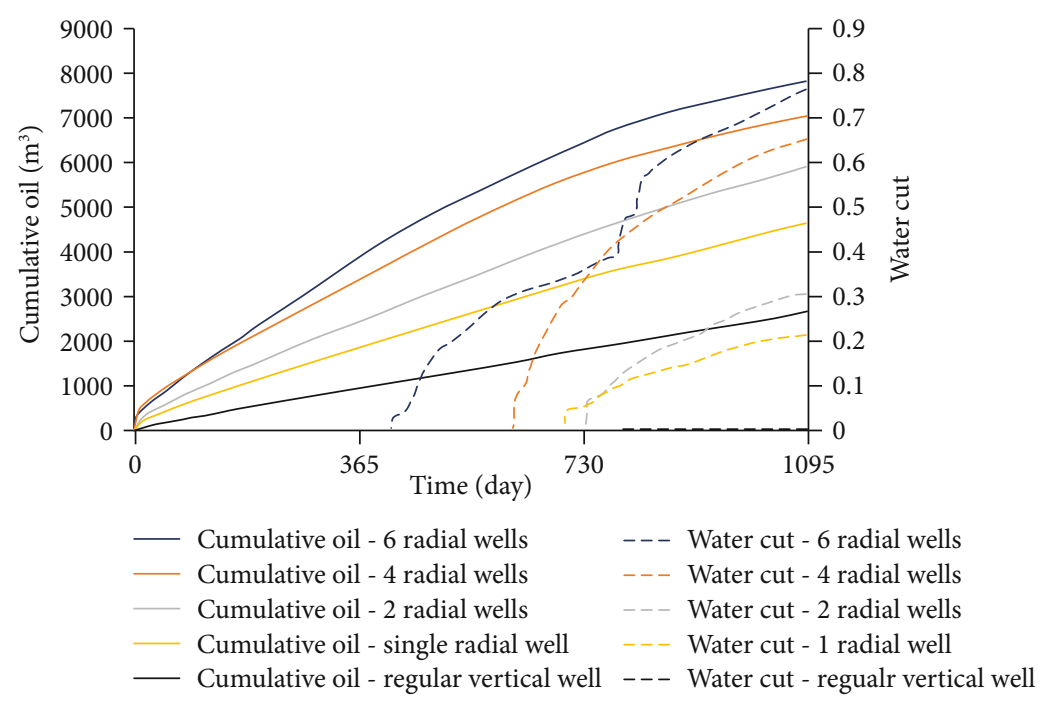

FIGURE 16: Variation of cumulative oil and water cut on time.

the total sweep area increases more slowly. Numerical simulation shows that the accumulative oil production in three years increases by $12.8 \%$ when four fractures are increased to six fractures. Considering the influence of horizontal maximum principal stress, the fracture initiation pressures in all six fractures are not unified; thus, the propagation morphology of six fractures is not always uniform. Some fractures are possibly not initiated (the fracture corresponding to radial borehole near the horizontal minimum principal stress). In the case of limited increase of deliverability and unstable fracture morphology caused by six fractures, four radial boreholes and four fractures are the optimum choice.

3.2. Final Optimization Scheme of Borehole Arrangement. According to multiple fracture morphology and sweep area, two principles of optimizing borehole arrangement scheme in the homogeneous reservoir are obtained as follows: the radial boreholes are symmetrically arranged along the horizontal maximum principal stress; the radial boreholes are uniformly distributed in the horizontal plane. According to the results of deliverability simulation, two parameters can be determined: better development results can be achieved with appropriate cost in four radial boreholes in a horizon; an optimum development effect can be achieved with a phase angle of $90^{\circ}$ of four radial boreholes.

To sum up, different fracture initiation pressures correspond to different azimuths. In order to ensure the uniform fracture initiation pressure of radial borehole and full propagation of hydraulic fracture corresponding to each radial borehole, four radial boreholes are arranged with the horizontal maximum principal stress as the symmetry axis. Because the actual fracture and radial borehole have a certain deflection angle, the final optimum borehole arrangement scheme is the intersectional angle of $45^{\circ}$ between four orthogonal radial boreholes and horizontal maximum principal stress. There is a range of optimum drilling hole (about $10^{\circ}$ of fracture deflection margin, and the detailed margin is determined based on geostress difference, rock parameters, etc.), so that the intersectional angle between expected fractures and horizontal maximum principal stress is $45^{\circ}$ (Figure 17). The actual fracture morphology in this borehole arrangement scheme is shown in Figure 18.

\section{Application and Production Analysis}

4.1. Application in Field. The radial borehole fracturing was applied in Shengli Oil Field recently, and the optimization scheme of radial perforation was adopted in the fracturing design. Since the reservoir of target well is the prototype of the model previous in this paper, the parameters has been shown in preceding chapters. According to the fracturing design, the expected length of fracture is about $80 \mathrm{~m}$. Microseismic crack monitoring was applied, and the results are shown in Figure 17.

Sketch of fracture morphology based on microseismic crack monitoring is arranged in order to reveal the fracture morphology clearly (Figure 19). According to the results of microseismic crack monitoring, the morphology of cracks propagated along each of the orthogonal radial wells is consistent with the conclusion of simulation in the previous chapters. Four major cracks along each radial borehole and a secondary crack connecting the adjacent major cracks were formed under the influence of radial boreholes. Because of the heterogeneity of reservoir, the length of fracture in different directions is discrepant and only one obvious secondary crack is formed. The formed multifracture improves the degree of reservoir stimulation greatly which is beneficial to improve the production.

4.2. Production Analysis. Since the trial production is still in progress and the data is undocumented, the production is analyzed by CMG-based simulation to propose advice on production. The block of target well is heavy oil reservoir, and huff and puff are the routine techniques in the exploitation.

Optimization scheme of radial perforation is adopted as the basic model, where the maximum constrain value of bottom hole pressure during steam injection is $23 \mathrm{MPa}$, and that 

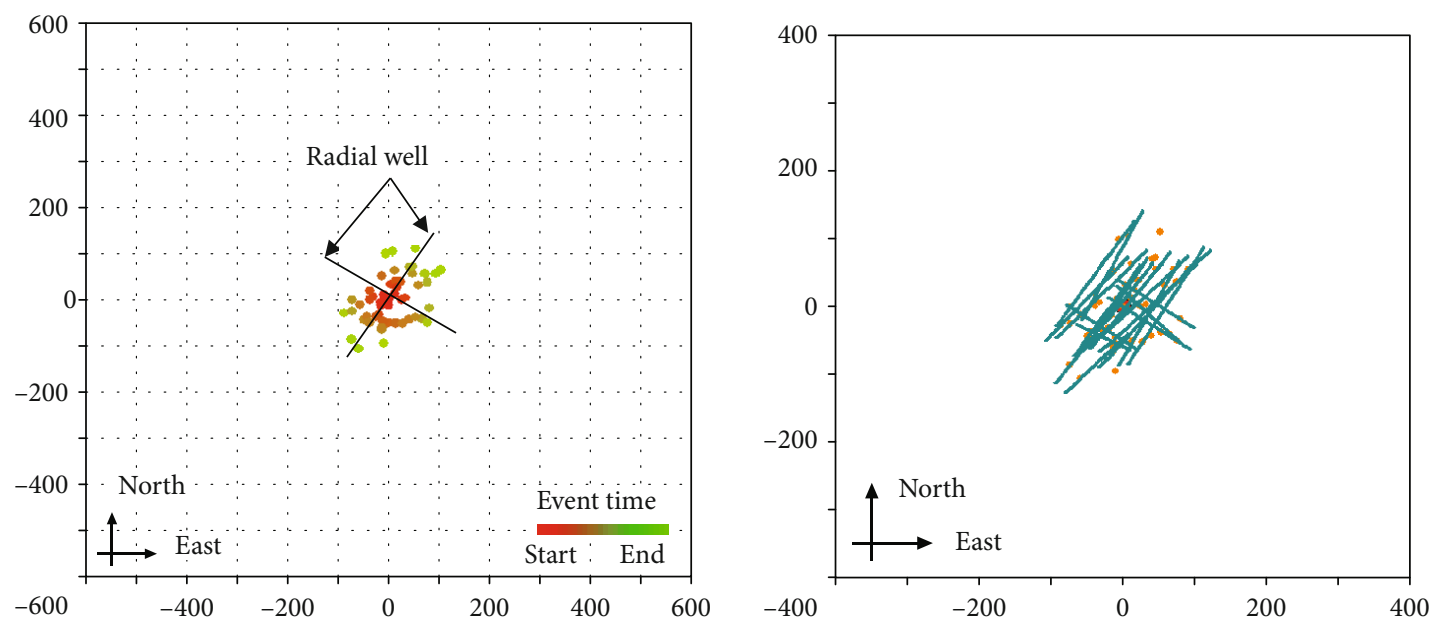

FIGURE 17: Results and analysis of microseismic crack monitoring.
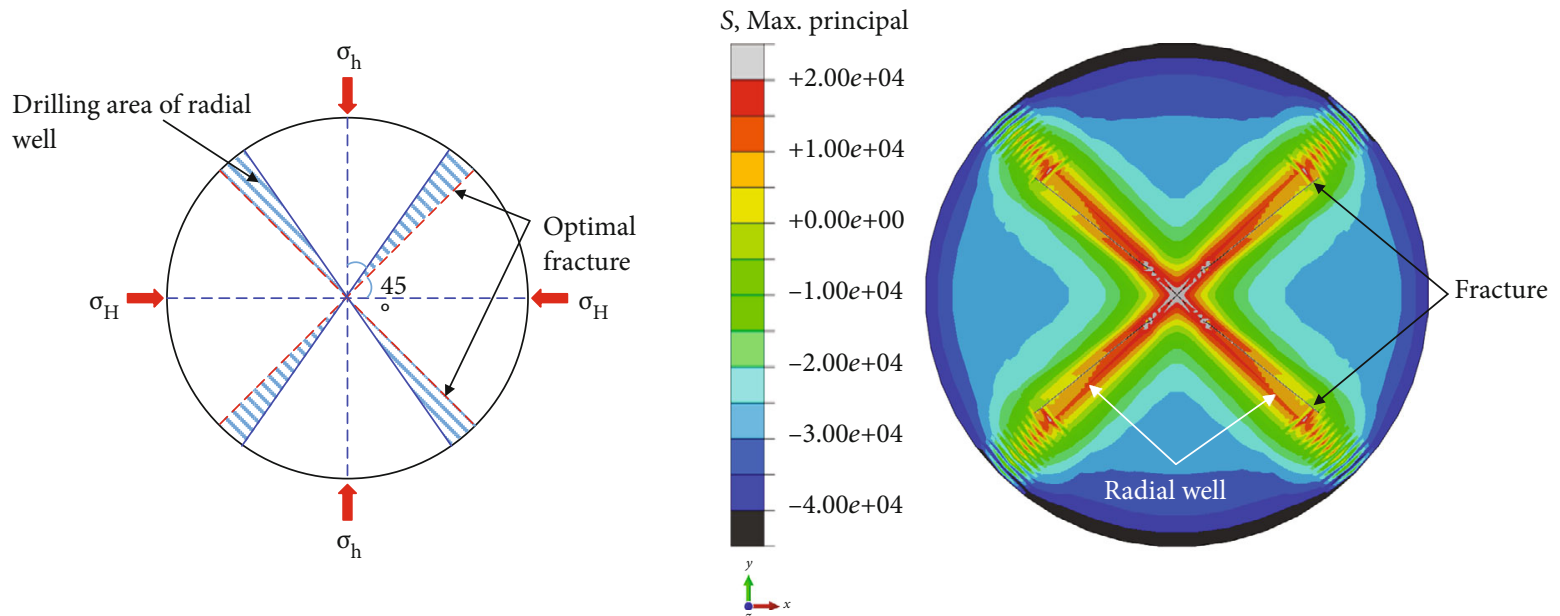

Figure 18: Optimization scheme of radial perforation.

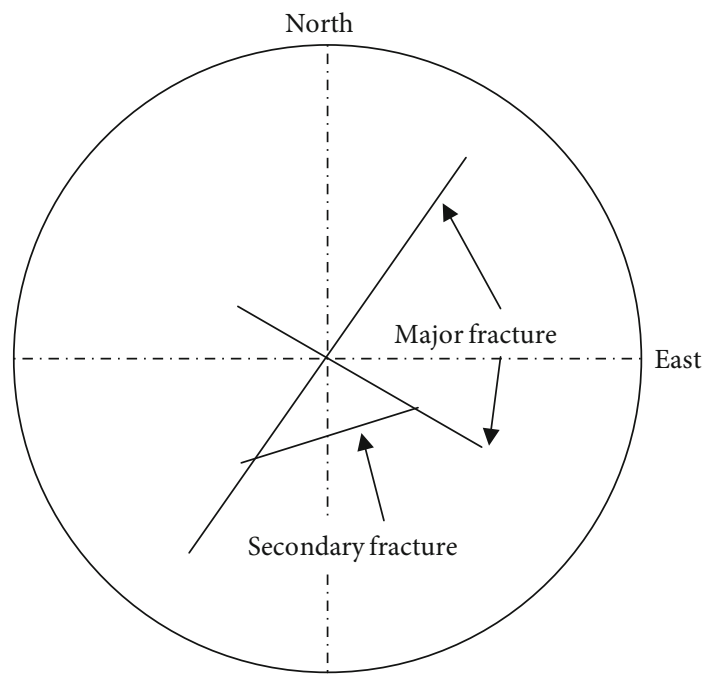

FIGURE 19: Sketch of fracture morphology based on microseismic crack monitoring. of ground water injection volume is $300 \mathrm{~m}^{3} / \mathrm{d}$; the minimum constrain value of bottom hole pressure during steam injection is $10 \mathrm{MPa}$, and the maximum constrain value of fluid production is $200 \mathrm{~m}^{3} / \mathrm{d}$; the period of huff and puff is one year.

The thermal recovery parameters of a model, i.e., the steam injection rate $180 \mathrm{t} / \mathrm{d}$, steam injection intensity $150 \mathrm{t} / \mathrm{m}$, steam dryness $60 \%$, and soaking time $4 \mathrm{~d}$, are determined according to existing studies $[29,30]$. The result of deliverability simulation is shown in Figure 20.

The deliverability declines in three years of production in four development methods (conventional fracturing, radial borehole fracturing, conventional fracturing+steam huff and puff, and radial borehole fracturing+steam huff and puff), and the deliverability declines more rapidly in radial borehole fracturing and radial borehole fracturing +steam huff and puff than other development methods. The reason is that the multiradial borehole and multifractures effectively increase the sweep area, significantly enlarging the drainage area of a single well and increasing 


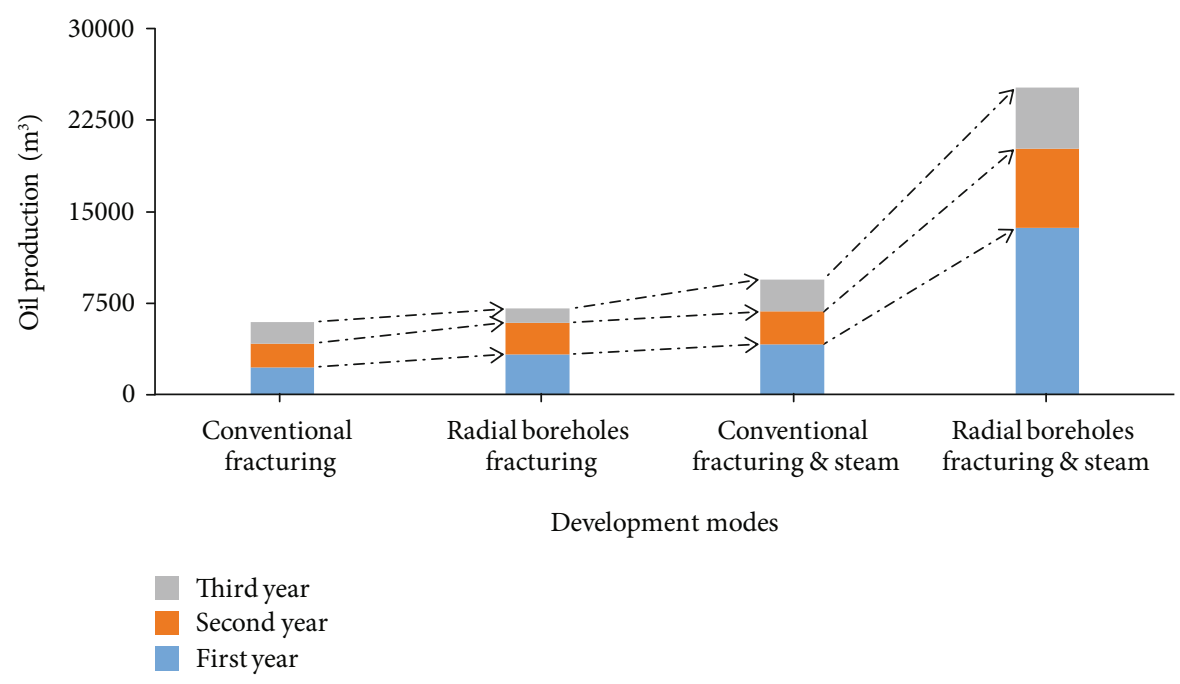

Figure 20: Capacity comparison of different development modes.

the deliverability rapidly in an early period. However, in the edge-water-driven reservoir or injector-producer well pattern, the larger sweep area can cause earlier water break. Considering the high fracture conductivity and the great difference between oil and water mobility, the oil production will decrease rapidly and the water cut will increase rapidly (Figures 14 and 16). Thus, in the development with radial borehole fracturing, the water block should be implemented as early as possible, avoiding a large-scale decrease of deliverability.

The accumulative oil production of three years in four radial boreholes and four fractures is 2.65 times that of conventional fracturing. A good result is achieved in the technology of huff and puff with multiradial borehole and multifractures. Thus, compared with cold recovery, the technology of multiple-radial borehole fracturing and steam huff and puff is more applicable in developing low permeability heavy oil reservoir.

\section{Conclusions}

(1) The induced stress field is formed during the radial borehole fracturing, making the hydraulic fracture propagate directionally. The increase of radial borehole vertical density will effectively enhance guidance of radial borehole to the hydraulic fracture. And among the anthropogenic factors, the radial borehole vertical density has the highest weight

(2) Affected by interference of dual-radial borehole, the complex multifractures are possibly generated in the interference stress field, which can reduce the flow resistance near wellbore and decrease the pressure loss along the path. As fracturing goes on, the multiple principal fractures propagating along each radial borehole occur in the induced stress field in the distant area, significantly increasing the drainage area and enhancing the deliverability
(3) The arrangement scheme of horizontal multipleborehole is optimized with maximum deliverability as the standard, with conditions of the homogenous reservoir model as follows: uniform boreholes in the horizontal plane and uniform intersectional angle between radial boreholes and horizontal maximum principal stress. Thus, the final optimum borehole arrangement scheme is the intersectional angle of $45^{\circ}$ between four orthogonal radial boreholes and horizontal maximum principal stress

(4) The deliverability declines obviously in the first three years after applying the radial borehole fracturing. Multiradial boreholes and multifractures effectively increase the drainage area of a single well and cause earlier water breakthrough. Thus, in the development with radial borehole fracturing, the water block should be implemented as early as possible to avoid a large-scale decrease of deliverability

\section{Data Availability}

The model data of fracture propagation used to support the findings of this study are included within the supplementary information file (.inp). The data of CMG is from the papers in the reference list $[28,29]$ which is cited.

\section{Conflicts of Interest}

No conflict of interest exists in the submission of this manuscript, and the manuscript is approved by all authors for publication. I would like to declare on behalf of my coauthors that the work described was original research that has not been published previously, and not under consideration for publication elsewhere, in whole or in part. All the authors listed have approved the manuscript that is enclosed. 


\section{References}

[1] T. Guo, S. Zhang, H. Ge, X. Wang, X. Lei, and B. Xiao, "A new method for evaluation of fracture network formation capacity of rock," Fuel, vol. 140, pp. 778-787, 2015.

[2] L. Liu, L. Li, D. Elsworth, S. Zhi, and Y. Yu, "The impact of oriented perforations on fracture propagation and complexity in hydraulic fracturing," Processes, vol. 6, no. 11, p. 213, 2018.

[3] T. Guo, Y. Li, Y. Ding, Z. Qu, N. Gai, and Z. Rui, "Evaluation of acid fracturing treatments in shale formation," Energy \& Fuels, vol. 31, no. 10, pp. 10479-10489, 2017.

[4] J. Li, S. Dong, W. Hua, X. Li, and X. Pan, "Numerical investigation of hydraulic fracture propagation based on cohesive zone model in naturally fractured formations," Processes, vol. 7, no. 1, p. 28, 2019.

[5] M. Qi, M. Li, T. Guo, C. Liu, S. Gao, and S. Tang, "Influence of oriented perforation design on refracture reorientation: simulation and experiment," Journal of Energy Resources Technology, vol. 140, no. 8, 2018.

[6] J. Li, G. Li, Z. Huang, X. Song, Z. He, and S. Zhang, "A discussion about the method to study the effect of ambient pressure on hydraulic jetting," Journal of Petroleum Science and Engineering, vol. 149, pp. 203-207, 2017.

[7] H. Shi, G. Li, Z. Huang, and S. Shi, "Properties and testing of a hydraulic pulse jet and its application in offshore drilling," Petroleum Science, vol. 11, no. 3, pp. 401-407, 2014.

[8] T.-M. Oh, A. K. Prasidhi, G.-C. Cho, and J.-H. Shin, "Effect of water jet geometric parameters on rock fracturing," KSCE Journal of Civil Engineering, vol. 18, no. 3, pp. 772-779, 2014.

[9] M. Sheng, G. Li, Z. Huang, S. Tian, and H. Qu, "Experimental study on hydraulic isolation mechanism during hydra-jet fracturing," Experimental Thermal and Fluid Science, vol. 44, pp. 722-726, 2013.

[10] T. Guo, Z. Qu, F. Gong, and X. Wang, "Numerical simulation of hydraulic fracture propagation guided by single radial boreholes," Energies, vol. 10, no. 10, p. 1680, 2017.

[11] Y. Tian, Z. Qu, T. Guo, and Y. Tian, “Theoretical research on radial wells orientating hydraulically created fracture directional extended," International Journal of Hydrogen Energy, vol. 42, no. 29, pp. 18358-18363, 2017.

[12] D. Zhang, S. Yuan, X. Tian, W. Zhang, and J. Zuo, "Research on fracturing extension by radial hydraulic jet in low permeability reservoirs," Journal of China University of Petroleum, vol. 40, no. 2, pp. 129-134, 2016.

[13] D. G. Gong, Z. Q. Qu, T. K. Guo, Y. Tian, and K. H. Tian, "Variation rules of fracture initiation pressure and fracture starting point of hydraulic fracture in radial well," Journal of Petroleum Science and Engineering, vol. 140, pp. 41-56, 2016.

[14] T. Guo, Z. Qu, D. Gong, X. Lei, and M. Liu, "Numerical simulation of directional propagation of hydraulic fracture guided by vertical multi-radial boreholes," Journal of Natural Gas Science and Engineering, vol. 35, pp. 175-188, 2016.

[15] T. Guo, B. Liu, Z. Qu, D. Gong, and L. Xin, "Study on initiation mechanisms of hydraulic fracture guided by vertical multiradial boreholes," Rock Mechanics and Rock Engineering, vol. 50, no. 7, pp. 1767-1785, 2017.

[16] X. Li, J. Li, L. Zhou, K. Zhang, Y. Liu, and Y. Chen, "Research on directional initiation of crack in radial perforation fracturing," Journal of Xi'an Shiyou University, vol. 32, no. 2, pp. 46-52, 2017.
[17] X. Li, W. Xiao, J. Li, Y. Liu, W. Zhang, and T. Guo, "Fractured morphology assisted by the radial borehole," Petroleum Geology and Oilfield Development in Daqing, vol. 36, no. 2, pp. 78-84, 2017.

[18] X. Li, J. Li, T. Wang, K. Zhang, T. Guo, and Z. Qu, "Crack morphology of the radial well fracturing based on the numerical simulation," Petroleum Geology and Oilfield Development in Daqing, vol. 37, no. 3, pp. 90-95, 2018.

[19] X. Fu, G. Li, Z. Huang, Y. Liang, Z. Xu, and X. Jin, "Experimental and numerical study of radial lateral fracturing for coalbed methane," Journal of Geophysics and Engineering, vol. 12, no. 5, pp. 875-886, 2015.

[20] X. Li, J. Li, W. Xiao, T. Guo, W. Zhang, and Y. Tian, "Simulation of influence of radial borehole on well stability," FaultBlock Oil \& Gas Field, vol. 23, no. 6, pp. 829-834, 2016.

[21] Z. Qu, Y. Yang, H. Lu, X. Sun, B. Wang, and J. Yao, "Productivity calculation of radial well distal fracturing and its application," Journal of Central South University, vol. 45, no. 7, pp. 2289-2294, 2014.

[22] Z. Qu, X. Li, J. Li et al., "Crack morphology of multiple radial well fracturing based on extended finite element method," Journal of China University of Petroleum, vol. 42, no. 1, pp. 73-81, 2018.

[23] X. Liu, Z. Qu, T. Guo, D. Wang, Q. Tian, and W. Lv, “A new chart of hydraulic fracture height prediction based on fluidsolid coupling equations and rock fracture mechanics," Royal Society Open Science, vol. 5, no. 10, article 180600, 2018.

[24] X. Liu, Z. Qu, T. Guo et al., "An innovative technology of directional propagation of hydraulic fracture guided by radial holes in fossil hydrogen energy development," International Journal of Hydrogen Energy, vol. 44, no. 11, pp. 5286-5302, 2019.

[25] X. Li, W. Xiao, Z. Qu et al., "Rules of fracture propagation of hydraulic fracturing in radial well based on XFEM," Journal of Petroleum Exploration and Production Technology, vol. 8, no. 4, pp. 1547-1557, 2018.

[26] X. Li, B. Wang, T. Guo, F. Gong, X. Tian, and Z. Huang, "Experiment on the friction test of the radial borehole based on gray correlation analysis," Petroleum Geology and Oilfield Development in Daqing, vol. 34, no. 6, pp. 77-82, 2015.

[27] T. Guo, F. Gong, L. Shen, Z. Qu, N. Qi, and T. Wang, "Multifractured stimulation technique of hydraulic fracturing assisted by radial slim holes," Journal of Petroleum Science and Engineering, vol. 174, pp. 572-583, 2019.

[28] T. Guo, Z. Rui, Z. Qu, and N. Qi, "Experimental study of directional propagation of hydraulic fracture guided by multi-radial slim holes," Journal of Petroleum Science and Engineering, vol. 166, pp. 592-601, 2018.

[29] H. Xu, Productivity Evaluation of Cyclic Steam Stimulation Assisted by Radial Borehole Fracturing in Low Permeability Heavy Oil Reservoir, [M.S. thesis], China University of Petroleum (East China), Dongying, China, 2016.

[30] X. Li, H. Xu, X. Liu, T. Wang, K. Zhang, and Z. Qu, "Fracture morphology and production performance of radial well fracturing," Lithologic Reservoirs, vol. 29, no. 06, pp. 154-160, 2017. 

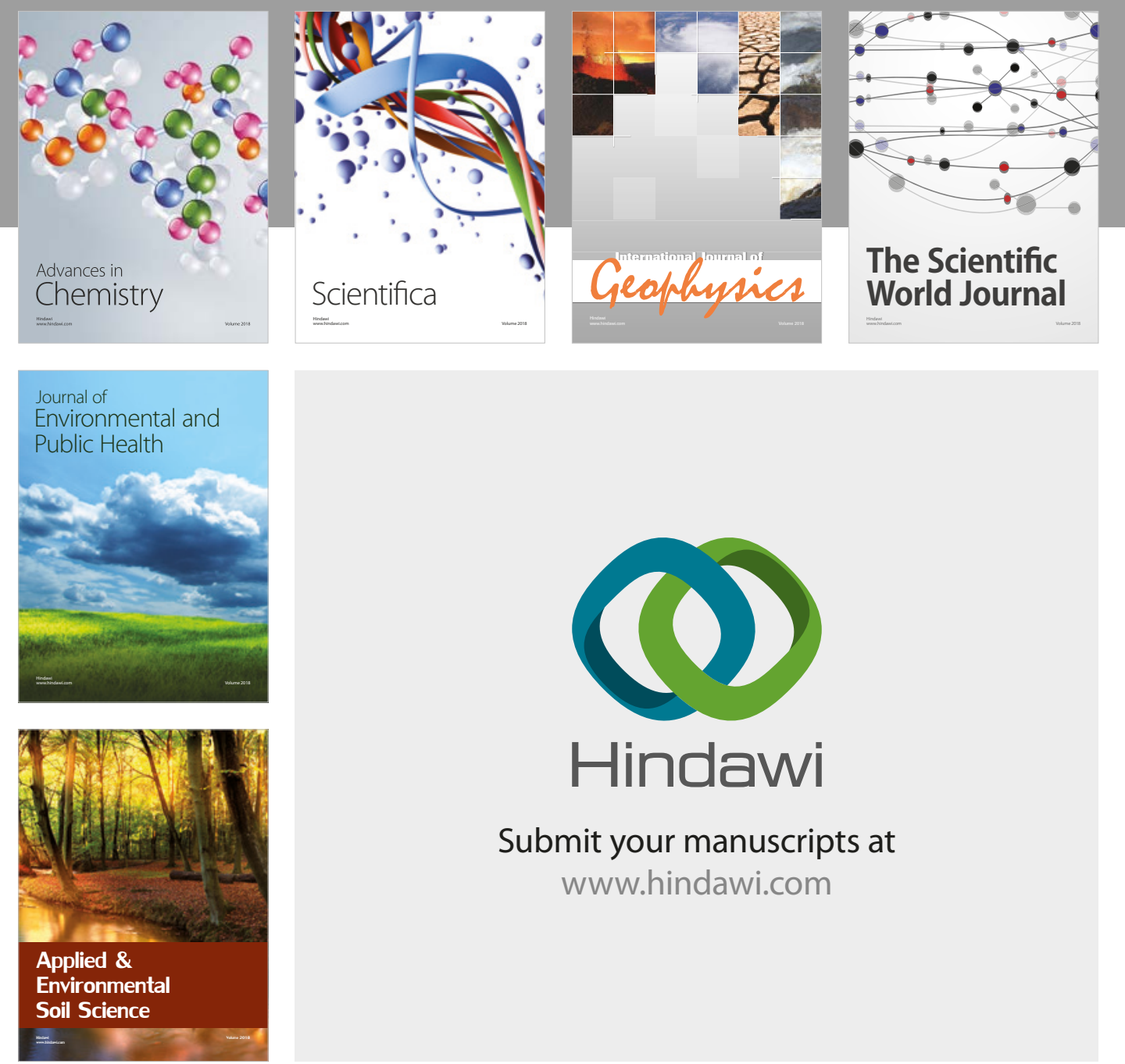

The Scientific

\section{World Journal}
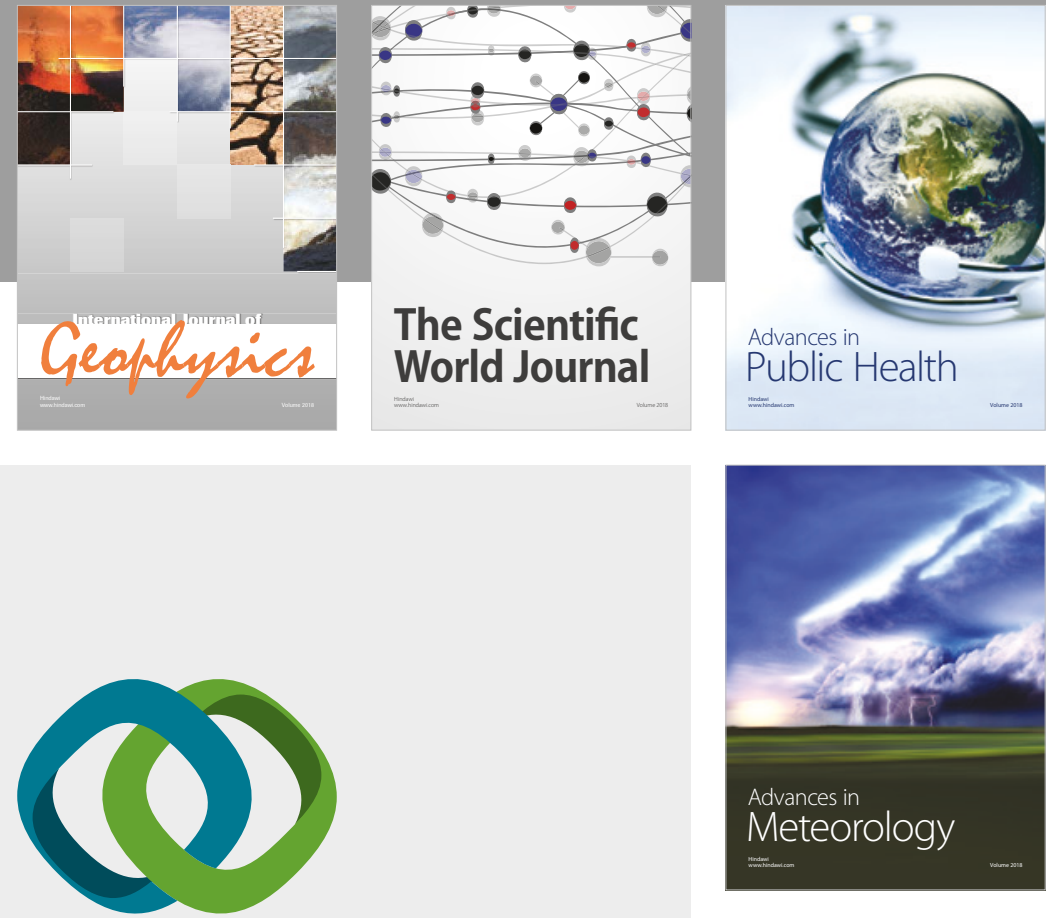

Advan

Public Health

\section{Hindawi}

Submit your manuscripts at

www.hindawi.com
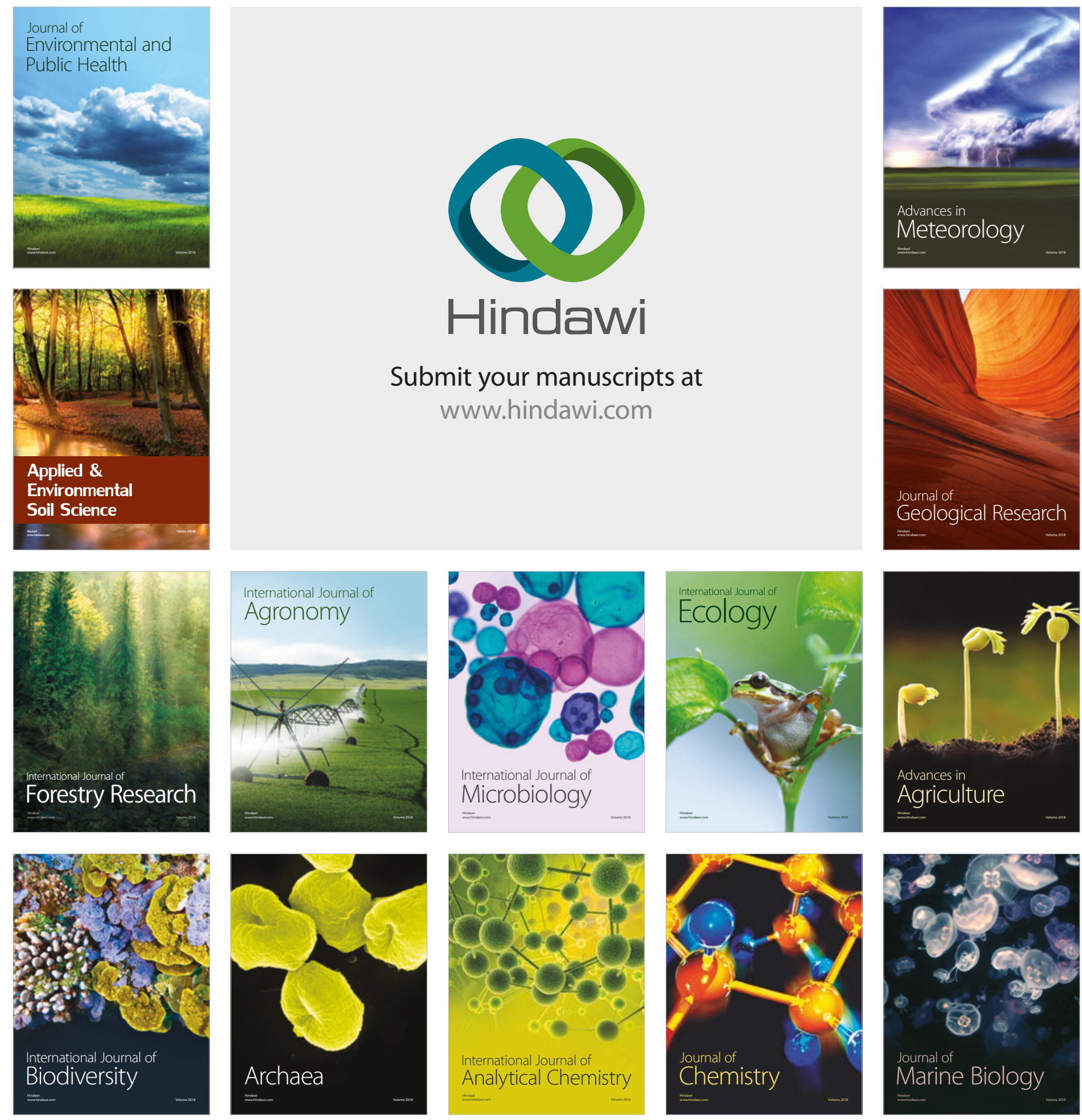